Pecvnia, 5 (2007), pp. 229-272

\title{
Estrategias de internacionalización de la gran banca española
}

\author{
María del Pilar Sierra Fernández \\ pilar.sierra@unileon.es \\ Universidad de León \\ Fac. de Ciencias Económicas y Empresariales \\ Campus de Vegazana, $\mathrm{s} / \mathrm{n}$ \\ 24071 León (España)
}

La timidez con la que comenzaron a internacionalizarse los bancos españoles, integrantes tanto del actual grupo BBVA como del Santander, aplicando estrategias defensivas y reducidos volúmenes de recursos y riesgos comprometidos, difícilmente hacían presagiar la intensidad y agresividad que ha adquirido en las dos últimas décadas, y que han convertido a dicho proceso en una decisión estratégica de crecimiento para la gran banca española.

De forma gradual, tanto el BBVA como el Santander, se han introducido en los principales mercados de Latinoamérica y en los más cercanos e importantes de la Unión Europea. De una implantación generalizada de banca comercial en los noventa, sobre Latinoamérica, se ha pasado a operaciones selectivas en términos operativos y geográficos; llegando a finales de 2007, a liderar diferentes servicios bancarios y parabancarios en la mayor parte de los países del área, con especial incidencia en Brasil, donde el Santander está especializando
The timidity with which they began to internationalize Spanish banks, both members of the current group BBVA and Santander, of applying defensive strategies and reduced volumes of resources and risks involved, hardly did presage the intensity and aggressiveness that has gained in the last two decades, and they have turned the process into a strategic decision to growth for the Spanish banking.

Gradually, both BBVA and Santander, has been internalised in the main markets of Latin America and the closest major of the European Union. From a widespread introduction of commercial banking in the nineties, in Latin America, has become selective operations. Actually, in late 2007, these banks lead the banking activities in most countries in the area, special emphasis on Brazil, where Santander is specializing their investments, and in Mexico, where BBVA has consolidated its 
sus inversiones, y en México, donde el BBVA ha consolidado su implantación y, desde el que se ha servido para iniciar actividades bancarias en el sur de los Estados Unidos. La mayor dimensión internacional del Santander le ha colocado también en posiciones líderes en los mercados ibérico, británico y en el segmento de financiación al consumo en la Europa Comunitaria.

Palabras clave: banca, banca española en el extranjero, internacionalización bancaria, expansión internacional de la gran banca española, estrategias de internacionalización. implementation and, since it had used to start internationalisation in the southern United States. The largest international dimension of Santander has also placed in leadership positions in the Iberian and the British market, and the segment of funding for consumption in the European Community.

Key words: Banking, Spanish banking abroad, international banking, international expansion of the large Spanish bank, internationalization strategies.

\section{INTRODUCCIÓN}

Un nuevo contexto económico, político y social, caracterizado por una mayor complejidad, creciente interdependencia, mayor incertidumbre y búsqueda de flexibilidad (Chevalier 1995: 13), ha venido propiciando la intensificación de las relaciones transfronterizas (Dunning 1994 y Ohmae 1991: 137) ${ }^{1}$ con crecientes actuaciones de internacionalización de las empresas y corporaciones empresariales.

Este fenómeno de internacionalización comienza, como sostiene Alonso (1994: 28) en el mismo momento en que el mercado exterior se constituye en referencia de las decisiones estratégicas que adoptará la empresa. En esa misma línea apunta Duran Herrera (1991: 21), considerando que cuando una empresa instala sus facilidades productivas o distribuidoras en el extranjero, inicia así su proceso de multinacionalización, transnacionalizando en su seno su ventaja competitiva.

No sólo las empresas industriales han diseñado crecimientos basados en la diversificación geográfica, sino también el sector servicios $y$, el bancario en particular, han sido protagonistas con la aplicación de estrategias de desarrollo transnacional.

Este fenómeno de transnacionalización bancaria ha sido desarrollado por la gran banca de los países desarrollados. Y la banca

1 De forma gradual, las fronteras en los mercados de factores productivos y de bienes y servicios exceden los límites nacionales, perdiéndose la dimensión nacional en el establecimiento de los retos empresariales y las oportunidades de negocio, produciéndose la desaparición efectiva de las fronteras nacionales (Ohmae 1991: 137). 
española ha sido, además, un protagonista fundamental en las últimas décadas con un intenso y selectivo crecimiento de su actividad internacional.

En el presente artículo, se ha querido caracterizar el proceso de internacionalización que han desarrollado los dos grandes bancos españoles, el grupo BBVA y el grupo Santander, en base a los datos recogidos en los informes anuales de dichas entidades bancarias.

Y dicho análisis se ha planteado con el fin de definir los modos de entrada, las estrategias, el destino geográfico y la intensidad del proceso de transnacionalización de la actividad bancaria de ambos bancos. $Y$ así, se han estudiado los diferentes métodos de internacionalización bancaria observando si se han realizado con recursos propios de la entidad (crecimiento interno) o si por el contrario, se han utilizado recursos ajenos, procedentes de adquisiciones, fusiones o cooperación con entidades locales del mercado destino de la inversión. También se han podido establecer tres etapas en las que ha variado notablemente el compromiso de recursos y de riesgos, así como el destino geográfico de la inversión.

\section{TEORÍAS Y ESTRATEGIAS EXPLICATIVAS DE LA INTERNACIONALIZACIÓN BANCARIA}

\section{A. Teorías}

Diversos enfoques teóricos han tratado de justificar la existencia de grupos bancarios internacionalizados (adaptados de las teorías de internacionalización aplicadas a los sectores industriales). Alguno de los modelos desarrollados analizan este tipo de decisiones desde una perspectiva estática (teoría de la internalización, el modelo ecléctico, etc.), considerando que la decisión de transnacionalizarse se adopta en un instante puntual en el tiempo; mientras que otros modelos ${ }^{2}$ aportan una visión dinámica al considerar que dicho proceso se incrementa de forma secuencial y como resultado de la experiencia acumulada, como explica la teoría de las fases del desarrollo.

2 También la teoría institucional ofrece una perspectiva dinámica para explicar la internacionalización de la empresa en general, aunque sin hacer alusión al sector bancario. En base a dicho modelo, la empresa elige distintos modos de entrada a lo largo del tiempo, explicando el modo en que se produce dicho cambio, y sin establecer un orden lógico en los modos de entrada adoptados a lo largo del tiempo. 
La internacionalización bancaria comienza a interesar a los economistas en la década de los setenta, explicándose la misma en base a razonamientos de carácter estático. Una primera aproximación a la construcción de un marco teórico sobre la misma es elaborada por Aliber (1976), que consideraba que los diferenciales de tipos de interés entre países justificaba, por una parte, que los grupos bancarios más eficientes procurarían establecer filiales en el exterior para aprovechar mayores márgenes de intermediación bancaria, y por otra, podrían reestructurar su balance buscando un endeudamiento más barato y una inversión a mayor precio. Dentro de los modelos oligopólicos de Inversión directa en el exterior, Grubel (1977) realiza otra interesante aportación al considerar que los bancos en su expansión internacional pueden trasladar y adaptar con éxito las habilidades y recursos empresariales que han sido desarrollados inicialmente en el ámbito nacional.

Las teorías de internalización y el paradigma ecléctico recogen las ideas anteriores y construyen modelos ampliamente utilizados en el estudio de la internacionalización. La teoría de Internalización (la cual está integrada en la Teoría de los Costes de Transacción ${ }^{3}$ ) justifica la razón de ser de la empresa multinacional en la existencia de fallos de mercado. La internacionalización tiene lugar cuando la internalización se realiza traspasando alguna frontera nacional. Rugman, en 1981, la aplicó al sector bancario, al considerar que los grupos bancarios prefieren sustituir las transacciones en el mercado para los productos intermedios (conocimiento, habilidades operativas, investigación, etc.) por operaciones controladas internamente y mediante las que, como indicaría posteriormente Kim (1993) pueden reducir costes, aumentar la flexibilidad, proteger el valor de los recursos intangibles, etc. Internalizando la actividad internacional se superaban imperfecciones de mercado (Casson 1990) como las restricciones a la movilidad de capitales, la diferente regulación bancaria, la intangibilidad de los servicios que precisa de un flujo directo de información banco-cliente, etc.

El paradigma ecléctico, introducido por Dunning en 1977, sería adaptado al sector bancario por Gray y Gray (1981) y por Yannopoulos (1983). Este paradigma considera que hay tres factores interrelacionados que determinan la propensión de las firmas para invertir en el extranjero:

3 Esta teoría considera que la empresa es una estructura organizativa que integra una serie de transacciones que el mercado realiza de una manera ineficiente o costosa. 
las ventajas en propiedad de la empresa o específicas de la empresa ("Ownership"), la capacidad y el interés para internalizar dichas ventajas ("internalize") y los factores de localización de los países de destino ("localisation"). Yannopoulos considera que los bancos internacionales poseen amplias ventajas en propiedad (por ejemplo, la diferenciación del producto bancario, en el que se asocia a los bancos más grandes como los más seguros), y que compensan a las ventajas poseídas por los bancos ya asentados en el mercado de destino de la inversión transnacional. Y, tanto Gray y Gray como el anterior autor, consideran que las decisiones de IDE están determinadas por ventajas de internalización y ventajas de localización. Las ventajas de internalización hacen referencia a las imperfecciones en los mercados de productos, a las imperfecciones en los mercados de "inputs" y a las economías de las operaciones internas, por ejemplo, derivadas de la preservación de las cuentas establecidas de clientes a los que se ha seguido desde el mercado nacional. Las ventajas en la localización internacional se centran en la posibilidad de entrar en un mercado con un potencial crecimiento, en el aseguramiento del control sobre las fuentes de materias primas y en el aprovechamiento de las diferencias en los sistemas de regulación, entre otras.

Por otra parte, y dentro de los modelos que explican el proceso de internacionalización de una forma secuencial, podemos destacar el modelo dinámico de Uppsala, basado en los trabajos de Johanson y Vahlne (1977) y Johanson y Wiedersheim (1975). Y si bien, en la literatura teórica no hay una aplicación al sector bancario, el proceso de internacionalización de la banca multinacional parece ajustarse en gran número de ocasiones al mismo ${ }^{4}$. Según este modelo, las decisiones de internacionalización atraviesan unas fases concretas y progresivas de desarrollo, de forma que la empresa se ira sirviendo de la experiencia acumulada para incrementar su presencia internacional, comprometiendo un mayor volumen de recursos en la materialización de formulas organizativas cada vez más complejas, sin incluir los modos cooperativos (desde exportaciones esporádicas, pasando por exportaciones estables a través de agentes independientes y la posterior apertura en el exterior de filiales comerciales hasta llegar a la apertura en el exterior de centros de producción). El conocimiento y el compromiso que la compañía estaría

\footnotetext{
Sin embargo, hay procesos de internacionalización más rápidos, que ocurren cuando se inician directamente con la realización de adquisiciones y por tanto se omiten las etapas previas.
} 
dispuesta a asumir, para penetrar en mercados extranjeros, se vería condicionado por las oportunidades y el riesgo percibidos por la empresa en su secuencia de aprendizaje en los mercados extranjeros. Riesgo que se reduciría cuando la distancia física y psíquica ("physchic distance"5) fuese menor.

Por otra parte, también debemos destacar la cooperación, en la carrera empresarial por la expansión y rentabilidad. Ésta se ha estado convirtiendo en una estrategia fundamental para responder adecuadamente al reto de la globalización, de acuerdo con las apreciaciones de Dussauge y Garrette (1991: 113). De esta forma, estamos asistiendo a un notorio crecimiento de las alianzas estratégicas, desde los años ochenta, como así apunta Dunning (1992: 250) e indica Faulkner. Faulkner acepta los objetivos apuntados por Porter y Fuller, que justificaban el establecimiento de alianzas en base a cuatro razones fundamentales: conseguir economías de escala y aprendizaje, aprovechar los conocimientos y capacidades de los socios, reducir el riesgo al compartir grandes inversiones de capital o en I+D y mantener cuota de mercado; y además añadía que la globalización de los mercados y de la tecnologías se convierte en la principal fuerza para el desarrollo de alianzas ${ }^{6}$, que en base a la cooperación, ayudan a competir a los socios (Faulkner 1995: 11).

Con esta revisión de teorías se ha pretendido exponer cuales son los principales criterios justificados desde la literatura de la internacionalización que se han convertido en razones fundamentales por las que los grupos bancarios han adoptado decisiones de internacionalización.

\section{B. Estrategias}

En la internacionalización de las entidades bancarias, al transnacionalizar su actividad ordinaria o implantar otras actividades parabancarias, utilizaremos dos criterios fundamentales para caracterizar dichas estrategias.

\footnotetext{
5 "Physchic distance" se define como las diferencias en lenguaje, nivel educativo, clima de negocios, desarrollo industrial, y cultura (Johanson y Widersheim 1975).

6 Estas cesiones contractuales aparecen cuando la empresa multinacional comparte una ventaja basada en conocimientos con un potencial competidor, con lo que externaliza la producción de sus ventajas a través del mercado. Podemos encontrar franquicias, licencia, contratos de dirección, contratos llave en mano, contratos de fabricación, acuerdos de asistencia técnica, contrato de servicios, acuerdo de coproducción, acuerdo de I+D en colaboración, etc.
} 
En primer lugar, y en función de la dinámica e intensidad de la actividad internacional en el tiempo se pueden diferenciar dos tipos de estrategia: oportunista y gradual. En la estrategia oportunista, la entrada en el mercado extranjero se realiza de una sola vez, bien sea a través de fusiones o mediante la compra total o parcial de empresas locales. Mientras que en la estrategia gradual, la internacionalización sigue un proceso exploratorio y secuencial. Y así, se plantean fases, en la que en el inicio se emplean fórmulas poco costosas que permitan la acumulación de experiencia; dando paso, en posteriores fases, y gracias a la experiencia internacional acumulada, a incrementos de su presencia física en el exterior, mediante fórmulas organizativas más complejas que supongan un mayor grado de control.

Por otra parte, teniendo en cuenta el tipo de modo de entrada utilizado en el crecimiento internacional de la empresa, se pueden establecer dos tipos de internacionalización: los basados en un crecimiento externo o en un crecimiento interno. En el crecimiento interno, la empresa utiliza sus recursos propios para crear valor internacional, con la puesta en marcha de una filial o sucursal en un país extranjero e incluso con la prestación de servicios por otros canales (por ejemplo, a través de Internet), en otros mercados diferentes al local. Mientras que en el crecimiento externo, la empresa emplea recursos ajenos a la entidad, implicando a otras entidades locales, con las que se firman acuerdos de colaboración y alianzas, o bien, sobre las que se realizan fusiones y adquisiciones, o tomas de participación mayoritarias y minoritarias. Como se puede observar, las oficinas de representación no se recogen en ninguna de las clasificaciones anteriores puesto que no implican un crecimiento real, ya que no hay prestación efectiva de servicios bancarios.

\section{ESPAÑOLA}

\section{PROCESO DE INTERNACIONALIZACIÓN DE LA GRAN BANCA}

Podríamos considerar el proceso de internacionalización de la gran banca española subdividido en tres etapas. Un primer período, de larga duración pero escasísima actuación internacional, una segunda etapa, de intensa actividad sobre Latinoamérica, y una tercera etapa, en la que la gran banca española, una vez consolidado su posición en los países latinoamericanos más importantes, retoma su interés por sus vecinos comunitarios y por la economía estadounidense. 
$1^{a}$ ETAPA: Tímida incursión internacional (1900-1992)

Con anterioridad a 1986 (fecha de incorporación de España a la Comunidad Económica Europea) y en especial de 1992 (implantación del mercado único comunitario) se puede afirmar que, en general, el proceso de multinacionalización de la banca española ha respondido principalmente al seguimiento del cliente español en su expansión internacional. Los principales bancos españoles del momento (Banco Santander, Banco Bilbao, Banco Central y Argentaria), con el fin de fidelizar a su cliente nacional más allá de las fronteras españolas e incluso de no perderle, le ha seguido para dar cobertura a sus operaciones de comercio exterior, a la apertura de filiales extranjeras de empresas españolas o para ofrecer unos servicios a los emigrantes españoles en países de Latinoamérica y Europa.

El seguimiento de los clientes nacionales constituye un factor tradicional para justificar las decisiones de internacionalización e implica una alta correlación entre la transnacionalización de la actividad industrial y bancaria. Este factor se ha explicado desde la Teoría de la Internalización ${ }^{7}$ (la expansión internacional internaliza y aprovecha la ventaja derivada del flujo de información que se establece entre el banco y su cliente), y también desde el paradigma ecléctico, al considerar que los bancos con clientes multinacionales presentan, frente a los bancos locales, la ventaja de trabajar a menores costes de transacción (ventaja de propiedad).

La escasa inversión transnacional realizada por los principales bancos españoles también se puede observar desde la óptica de la teoría de Uppsala, al considerar que dada la inexperiencia de actuación en mercados internacionales, reducen el riesgo, iniciando una tímida actividad en mercados cercanos "psíquicamente" como es el caso de América Latina, y mercados cercanos físicamente como en el caso de los europeos.

En esta defensiva estrategia, que aplica la banca española iniciando su andadura internacional, el principal modo de entrada utilizado es la apertura de oficinas de representación y, en menor medida, la apertura de filiales (véase Cuadro 1). Con ello, aún comprometiendo escasos recursos y asumiendo pocos riesgos en sus mercados más "cercanos",

Se han realizado varios estudios empíricos que tratan de establecer la correlación entre los fenómenos de internacionalización bancaria e industrial, y que en su mayor parte se han centrado en el caso estadounidense, como en el caso de Goldberg y Saunders (1981), Grosse y Goldberg (1991) y Brealey y Kaplanis (1996), etc. 
lograrán no sólo dar un apoyo básico a sus clientes nacionales en el exterior, sino también comenzar a extraer experiencia de su aventura internacional.

Con estas decisiones de internacionalización se comprometió una reducida inversión y se utilizaron fórmulas de entrada de bajo riesgo; estrategia justificada en la simultaneidad de tres entornos diferenciados. Así, mientras el sector bancario español seguía siendo un mercado protegido que ofrecía importantes márgenes de rentabilidad y, que operaba ajeno a un sistema comunitario en reestructuración, el mercado latinoamericano no sólo imponía estrictas barreras legales a la inversión extranjera y limitaciones al comercio internacional de servicios financieros, sino que además arrastraba las delicadas coyunturas socio-políticas que se generalizaron en América del Sur en los setenta, complicadas con la terrible factura que la deuda externa se cobró en la década de los ochenta, caracterizándose, por tanto, los mercados latinoamericanos como mercados de elevado riesgo e incertidumbre.

La experiencia internacional en Latinoamérica del actual grupo Santander es iniciada por el Banco Santander. Es el grupo bancario español con mayor experiencia acumulada en América Latina, con más de cincuenta años de presencia en la región, iniciándose en 1947 con el establecimiento de una oficina de representación en la Habana ${ }^{8}$ y en México, y que ampliaría a lo largo de la década de los sesenta y setenta con la apertura de otras oficinas de representación (Argentina, Brasil, Chile, Méjico, Venezuela y Puerto Rico) junto con la inauguración de dos sucursales, una en Argentina y otra en Panamá9. También el Banco Central Hispano se interesó por América Latina, pero mucho más tímidamente, a través de la apertura de oficinas de representación.

El aterrizaje del Banco Bilbao en Latinoamérica se produce con mayor retraso y menor impacto que la de los dos bancos anteriores, puesto que se inicia a principios de la década de los ochenta, y además con una motivación diferente, puesto que se materializa en la apertura de oficinas de representación en dos paraísos fiscales, en Panamá y Puerto Rico. En este caso, fue determinante el aprovechar las imperfecciones de

\footnotetext{
Esta oficina tuvo carácter temporal, puesto que fue cerrada años más tarde. Se estableció con fines estrictamente informativos.

9 El primer banco en el extranjero fue el Banco Santander-Argentina, fundado en 1963. En 1966, abrió en Panamá.
} 
los mercados financieros, que postula la Teoría de la Internalización, reduciendo el impacto de la regulación sobre los movimientos de capitales. Por otra parte, dentro de la corporación Argentaria, tan sólo el BEX mantenía participaciones en América Latina. En este caso, dichas inversiones tenían por objeto financiar las operaciones de comercio exterior realizadas entre España y algunos países de la zona, siguiendo así a clientes internacionalizados.

Cuadro 1: Estrategias de internacionalización de la gran banca española $1^{a}$ etapa: Tímida internacionalización (1900-1992)

\begin{tabular}{|c|c|c|}
\hline Criterios & Grupo Santander & Grupo BBVA \\
\hline Estrategias & \multicolumn{2}{|c|}{ Defensiva y oportunista } \\
\hline Actividad & \multicolumn{2}{|c|}{ Bancaria (Latinoamérica y Europa) } \\
\hline $\begin{array}{l}\text { Periodo de } \\
\text { entrada }\end{array}$ & $\begin{array}{l}\text { Europa: } \\
\text { - B. Santander entre en los } 50 \text { y el B. Central lo } \\
\text { hará a partir de los } 80 \text {, mientras que el } \\
\text { Hispano en los } 90 \text {. } \\
\text { Latinoamérica (principal destino): } \\
\text { - B. Santander entra en } 1947 \text { y practica una lenta } \\
\text { internacionalización. } \\
\text { - El B. Central entra tímidamente en los } 80 \text { y el } \\
\text { B. Hispano Americano lo hará de la mano del } \\
\text { BCH a partir de } 1991 . \\
\text { Otros destinos: } \\
\text { - El B. Santander abre una oficina de } \\
\text { representación en los } 70 \text { en EE.UU. y en los } \\
80 \text { establecerá una alianza en Japón. }\end{array}$ & $\begin{array}{l}\text { Europa (principal destino): } \\
\text { - B. Bilbao abre en } 1902 \text { la primera sucursal en } \\
\text { Paris, creciendo muy lentamente. } \\
\text { - En los } 80 \text { entrará el BBV. Argentaria no se } \\
\text { había implantado antes de la fusión. } \\
\text { Latinoamérica: } \\
\text { - B. Bilbao abrirá sucursales en los } 80 \text { y el B. } \\
\text { Vizcaya abriría solamente oficinas de } \\
\text { representación en los } 70 \text {. Argentaria también } \\
\text { tenía actividades tempranas. } \\
\text { Otros destinos: } \\
\text { - En los } 60 \text { y } 70 \text { abre oficinas de represen- } \\
\text { tación en Nueva York el B. Vizcaya. Y en los } \\
80 \text { lo hará el B. Bilbao. }\end{array}$ \\
\hline $\begin{array}{l}\text { Métodos de } \\
\text { entrada }\end{array}$ & \begin{tabular}{|l|} 
Escaso compromiso de recursos y riesgos: \\
- Oficinas de representación (Latinoamérica, \\
Europa y EE.UU.). \\
- Crecimiento interno (apertura de sucursales y \\
filiales en la década de los 50,60 y 70 ). \\
- Crecimiento externo (escasas adquisiciones \\
minoritarias en Latinoamérica, alianzas sobre \\
Europa).
\end{tabular} & $\begin{array}{l}\text { Escaso compromiso de recursos y riesgos: } \\
\text { - Oficinas de representación (Latinoamérica, } \\
\text { Europa y EE.UU.). } \\
\text { - Crecimiento interno (sucursales en Europa y } \\
\text { alguna en Latinoamérica, además de en } \\
\text { paraísos fiscales). } \\
\text { - Crecimiento externo (escasas adquisiciones } \\
\text { minoritarias en Latinoamérica y Europa). }\end{array}$ \\
\hline Motivaciones & \multicolumn{2}{|c|}{$\begin{array}{l}\text { Ventajas de localización (diferencias de regulación, mercados en crecimiento, etc.). } \\
\text { Ventajas de internalización (seguimiento de clientes, superar restricciones a la movilidad de capitales, } \\
\text { etc.). } \\
\text { Ventajas en propiedad (obtención de economías de aglomeración en plazas financieras } \\
\text { principales). } \\
\text { Mercados cercanos "psíquicamente" y físicamente. }\end{array}$} \\
\hline
\end{tabular}

Elaboración propia

En la implantación en Europa, resultó pionero el banco Bilbao, al abrir su primera sucursal en Paris en 1902 y en Londres en 1918, aplicando estrategias de crecimiento interno (véase Cuadro 1). A la que siguieron en los años 60 y 70 la apertura de otras oficinas de representación 
y la toma de participaciones minoritarias sobre Europa, que además también realizará el Banco de Vizcaya. Una vez digerida la fusión de ambos, se relanzó su expansión, con la creación de una filial propia en Portugal y Suiza, además de la instalación de oficinas de representación y de sucursales en el resto de Europa.

La expansión por Europa del grupo Santander se produciría décadas más tarde, puesto que se inició en 1955 con la apertura de una oficina en Londres y, de forma más lenta, ya que en los años 70 se retoma la apertura de nuevas sucursales en Paris y Francfort junto con otras oficinas de representación en otras plazas financieras, además de estar limitada a la actuación en exclusiva del Banco de Santander. En los ochenta, el Banco Santander modifica su estrategia superando el modo de entrada tradicionalista en base al establecimiento de sucursales (crecimiento interno) y de oficinas de representación, para aplicar una política de adquisiciones mayoritarias de capital de empresas locales, localizada en países cercanos geográficamente y con cierto conocimiento del mercado (Portugal, Italia, Alemania), además de establecer dos alianzas transnacionales, en 1987, con el CC-Bank y el Royal Bank que han resultado fundamentales en su expansión en el nuevo siglo. En los noventa, y a raíz de la fusión del BCH (1991), se incorporan a esta expansión europea el Banco Central y el Banco Hispano Americano, estableciendo alianzas con intercambio de participaciones en Italia, Alemania, Portugal y Francia.

\section{2a ETAPA: Impulso a la internacionalización (1993-2000)}

\section{2.a. Nuevo entorno Competitivo}

La creación del Mercado Único en 1992 se ha convertido en fundamental motor del proceso de internacionalización de nuestro sistema financiero. Puesto que ha enfrentado al sector bancario a un nuevo entorno competitivo determinado por una incipiente liberalización e innovación financiera, y a modificaciones normativas que han acelerado su desregulación y provocado su modernización e internacionalización.

Después de décadas de férreo control y protección sobre el sistema bancario español ${ }^{10}$ se inicio una tímida liberalización que se

10 Hasta finales de los ochenta, la estructura de la industria bancaria era claramente oligopolística, y se repartía un pequeño mercado protegido en el que los precios de activo y pasivo se ajustaban a las necesidades gubernamentales, pero implicaban rentas ciertas y abundantes para las escasas entidades bancarias abiertas en España. 
reforzó y consolidó con la consecución de la eliminación de las barreras legales a los movimientos de capital en la Unión Europea en 1991, junto con la exigencia de la plena libertad de prestación de servicios financieros (en virtud de la Segunda Directiva). Esta desregulación progresiva exigió el desarrollo de una normativa flexible y liberalizadora que ha propiciado un aumento de la competencia, con entrada de competidores bancarios comunitarios, y un incremento de la complejidad en el diseño de las estrategias bancarias que han tenido que hacer frente a una reducción en los tipos de interés $\mathrm{y}$, por tanto de los márgenes financieros, y a la aparición de nuevos productos financieros, ajenos al negocio tradicional bancario (fondos de inversión, planes de pensiones, etc.), que provocarían una creciente desintermediación financiera.

Por otra parte, el proceso de globalización financiera ha puesto de manifiesto las diferentes estructuras y necesidades bancarias de las regiones mundiales. Y así, mientras la banca de los países industrializados tiene exceso de capital y está sometida a intensas presiones para reducir costes de estructura y afrontar la reducción de márgenes en sus mercados, la mayoría de ellos maduros y con poca capacidad de crecimiento; la banca de los países en desarrollo está necesitada de capital, de gestión y de recursos humanos y materiales para hacer frente a una explosiva demanda de servicios financieros, que se ofrece con márgenes muy amplios.

La búsqueda de una mayor dimensión, a través de fusiones y adquisiciones bancarias, constituye una modificación fundamental derivada de las reformas bancarias internas y de la necesaria adecuación a las nuevas condiciones financieras exigidas con la consecución del mercado único. Esta concentración de entidades ${ }^{11}$, que dará como resultado la constitución de dos grandes grupos bancarios en España, BBVA y grupo Santander ${ }^{12}$, responde a un doble fin. Por una parte, obtener las sinergias

11 Se produjo un profundo proceso de reestructuración bancaria en España; dando como resultado la creación de dos mega bancos: BBVA y BSCH y la de un gran grupo bancario, el Banco Popular, que conviven con algunos grupos medianos como el Grupo Sabadell-Atlántico, Bankinter, Banco Pastor y Barclays Bank, junto con un conjunto cada vez menor de bancos pequeños, los cuales, en cualquier caso, están vinculados, en su mayor parte, a la gestión de alguno de los anteriores.

12 Los dos megabancos, BBVA y el actual grupo Santander son el resultado de un proceso de concentración que se pactó entre entidades nacionales en la década de los noventa. En 1988, se fusionaron los bancos Bilbao y Vizcaya, dando lugar al BBV. En 1991, el Banco Central se unió al Banco Hispano-Americano, creando el $\mathrm{BCH}$, a la vez que se produjo la reorganización de varios grupos bancarios públicos, dando lugar a la Corporación Argentaria. La crisis de principios de los 
necesarias para afianzar su posición en el mercado nacional, además de defenderse frente a posibles opas hostiles dentro un mercado maduro como es el bancario. Por otra parte, con la constitución de mayores grupos bancarios se contribuye en fortalecer su dimensión y su credibilidad en el mercado bancario. Tal y como afirmaba Yannopoulos (1983) al considerar que los bancos más grandes serían percibidos como los más seguros.

En consecuencia, todas estas modificaciones en el entorno competitivo determinaron no sólo la modernización y concentración de entidades, sino también el interés creciente por crecer explotando transnacionalmente sus recursos, capacidades organizativas y tecnológicas.

Y así, desde mediados de los noventa el proceso de internacionalización de la gran banca española ${ }^{13}$ cobra una particular y singular fuerza. Se acelera notablemente dicho proceso, en base a la aplicación de una estrategia de carácter gradual y ofensiva en Latinoamérica ( $y$ defensiva en Europa), que se basa en un notable crecimiento externo de la actividad internacional, el cual se apoya especialmente en la inversión directa extranjera $y$, en menor medida, en las alianzas estratégicas que son firmadas para el desarrollo internacional sobre los países desarrollados. Proceso, que además, responde a múltiples motivaciones, que ahora se explican desde una perspectiva mucho más plural que combina las ventajas competitivas esgrimidas en el postulado ecléctico y que se siguen verificando desde la proximidad física y "psíquica" de la escuela de Uppsala.

Durante toda la década de los noventa, la gran banca española, en su proyección internacional, ha mostrado interés por dos fundamentales mercados: Europa e Iberoamérica (entre ambos, concentraron el $73 \%$ del total de inversión en el exterior, realizada entre 1993 y el año 2000, por la banca y otros intermediarios financieros, como se pone de manifiesto en la Tabla 1). Mientras el primero de ellos es el resultado lógico derivado del proceso de integración comunitaria; el segundo está en relación con la cercanía "psíquica" que postulaba la

noventa paralizó el proceso, que retomó en 1994 el Banco Santander con la adquisición, mediante subasta, de uno de los grandes bancos españoles, Banesto. Por último, en 1999, el Banco Santander y el $\mathrm{BCH}$, se unieron, formando el grupo $\mathrm{BSCH}$, produciéndose paralelamente la fusión del BBV y Argentaria, surgiendo el actual BBVA. Entre medias, se han producido absorciones y tomas de participaciones mayoritarias en bancos pequeños que han permitido constituir grandes conglomerados financieros y reestructuraciones internas, que por ejemplo, han llevado al antiguo BSCH a tener una imagen de marca única como Santander.

13 Los bancos medianos y pequeños, muy condicionados por su naturaleza y tamaño, han desarrollado estrategias de crecimiento básicamente dentro de las fronteras españolas. Solo los bancos medianos han abierto alguna oficina de representación e incluso sucursal en los países más cercanos. 
Escuela de Uppsala y con razones de localización que se explican dentro del postulado ecléctico, puesto que dicha inversión se explica por la gran afinidad sociocultural y sobre todo por el interés en aprovechar la débil estructura bancaria, la escasa competencia inversora en la región y las posibilidades de crecimiento del mercado emergente de América Latina.

Además de estos dos principales destinos, también son elevadas las inversiones hacia los paraísos fiscales, que permiten a la banca salvar regulaciones más restrictivas; y por otra parte, en está década ya resultaba evidente el interés por tomar posiciones bancarias en Estados Unidos (véase Tabla 1).

Tabla 1: Inversión española bruta en el exterior de la banca y otros intermediarios financieros. 1993-2006

\begin{tabular}{|l|r|r|r|r|r|r|r|r|}
\hline \multirow{2}{*}{ Áreas geográficas } & \multicolumn{2}{|c|}{$\mathbf{1 9 9 3 - 2 0 0 0}$} & \multicolumn{2}{|c|}{$\mathbf{2 0 0 1 - 2 0 0 6}$} & \multicolumn{2}{c|}{$\mathbf{1 9 9 3 - 2 0 0 6}$} & \multicolumn{2}{c|}{ Enero-Junio 2007 } \\
\cline { 2 - 9 } & Millones $\boldsymbol{\epsilon}$ & \multicolumn{1}{c}{$\%$} & Millones $\boldsymbol{\epsilon}$ & \multicolumn{1}{c}{ \% } & Millones $\boldsymbol{\epsilon}$ & \multicolumn{1}{c}{$\%$} & \multicolumn{1}{c|}{ Millones $\boldsymbol{\epsilon}$} & \multicolumn{1}{c}{$\%$} \\
\hline O.C.D.E. & $17.429,72$ & 59,20 & $29.278,94$ & 92,25 & $46.708,66$ & 76,34 & 653,94 & 57,79 \\
\hline UE15 & $8.466,27$ & 28,75 & $18.023,35$ & 56,79 & $26.489,61$ & 43,30 & 123,18 & 10,88 \\
\hline UE25 & $8.466,27$ & 28,75 & $18.181,91$ & 57,29 & $26.648,18$ & 43,55 & 123,18 & 10,88 \\
\hline AMÉRICA NORTE & $4.262,25$ & 14,48 & $6.416,14$ & 20,22 & $10.678,40$ & 17,45 & 517,65 & 45,74 \\
\hline LATINOAMÉRICA & $13.030,05$ & 44,25 & $6.266,41$ & 19,74 & $19.296,46$ & 31,54 & 13,11 & 1,16 \\
\hline RESTO AMÉRICA & $2.293,26$ & 7,79 & 53,40 & 0,17 & $2.346,66$ & 3,84 & 0,00 & 0,00 \\
\hline ASIA Y OCEANÍA & 190,84 & 0,65 & 10,13 & 0,03 & 200,97 & 0,33 & 477,71 & 42,21 \\
\hline ÁFRICA & 16,66 & 0,06 & 0,00 & 0,00 & 16,66 & 0,03 & 653,94 & 0,00 \\
\hline Total seleccionado & $29.444,09$ & 100,00 & $31.739,22$ & 100,00 & $61.183,31$ & 100,00 & $1.131,65$ & 100,00 \\
\hline
\end{tabular}

Elaboración propia en base a los datos proporcionados por la Dirección General de Comercio e Inversiones Exteriores.

Nota: El epígrafe que recoge los países del resto de América incluyen a las pequeñas islas del continente americano, relacionadas en su mayor parte con centros off-shore o paraísos fiscales (Bermudas, Islas Caimán, Islas Vírgenes británicas, Antillas Neerlandesas, etc.).

\section{2.b. Internacionalización en América Latina}

Latinoamérica $^{14}$ se ha convertido en el principal destino de la banca española, durante la década de los noventa. Entre 1993 y el año 2000, se han destinado 13.030,05 millones de euros (implicaron el 44,25\% del total) hacia estos mercados en expansión; frente al $28,75 \%$ invertido en

14 Esta región no sólo ha suscitado interés en el sector financiero español, también otros sectores modernizados en los noventa han dirigido inversiones hacia Latinoamérica. Tal es el caso de los relacionados con la extracción de materias primas, transporte y comunicaciones, etc. La estrategia seguida por los inversores españoles se ha concretado en la compra de activos (empresas) ya existentes, en lugar de la creación de nuevas compañías, aprovechando las privatizaciones que se generalizaron en la década de los ochenta en la mayor parte de los países de América Latina. 
la UE-15, el 14,48\% realizado en América del Norte o el 7,79\% destinado principalmente a paraísos fiscales localizados en Centroamérica (véase Tabla 1). Y en total, entre 1993 y finales de 2006, la inversión bruta efectiva de la banca y otros intermediarios financieros en Latinoamérica ha sumado 19.296,46 millones de euros, que representa un tercio de todas las inversiones transnacionales realizadas en dicho período.

Tabla 2: Inversión de la banca española en Latinoamérica. 1993-2006

\begin{tabular}{|c|c|c|c|c|}
\hline \multirow[b]{2}{*}{ Países } & \multirow{2}{*}{$\begin{array}{l}\text { 1993-2000 } \\
\text { Millones } €\end{array}$} & \multirow{2}{*}{$\frac{2001-2006}{\text { Millones } €}$} & \multicolumn{2}{|c|}{ 1993-2006 } \\
\hline & & & Millones $€$ & $\%$ \\
\hline ARGENTINA & $1.233,44$ & 162,35 & $1.395,78$ & 7,23 \\
\hline BOLIVIA & 90,98 & 0,04 & 91,02 & 0,47 \\
\hline BRASIL & $6.267,69$ & 910,78 & $7.178,47$ & 37,20 \\
\hline CHILE & 805,15 & 14,10 & 819,26 & 4,25 \\
\hline COLOMBIA & 0,00 & 48,94 & 48,94 & 0,25 \\
\hline CUBA & 4,54 & 2,95 & 7,50 & 0,04 \\
\hline MÉXICO & $3.514,42$ & $3.859,54$ & $7.373,96$ & 38,21 \\
\hline PANAMÁ & 168,08 & 0,21 & 168,29 & 0,87 \\
\hline PARAGUAY & 9,53 & 0,90 & 10,44 & 0,05 \\
\hline PERÚ & 226,55 & 10,11 & 236,66 & 1,23 \\
\hline REP. DOMINICANA & 22,26 & 22,33 & 44,60 & 0,23 \\
\hline URUGUAY & 59,90 & 171,01 & 230,91 & 1,20 \\
\hline VENEZUELA & 625,19 & $1.062,74$ & $1.687,93$ & 8,75 \\
\hline TOTAL & $13.030,05$ & $6.266,41$ & $19.296,46$ & 100,00 \\
\hline
\end{tabular}

Elaboración propia en base a los datos proporcionados por la Dirección General de Comercio e Inversiones Exteriores.

La inversión hacia esta área se refuerza a partir de 1993, con inversiones generalizadas en las principales economías latinoamericanas (Argentina, Brasil, Chile, Venezuela, México), que se incrementarán en la mayor parte de los países de América del Sur hasta el año 2000. Ahora bien, una vez que la banca española se ha instalado ocupando posiciones privilegiadas en el mercado de préstamos y créditos, así como de pensiones y en la gestión de fondos de inversión, comenzaría a realizar una inversión más selectiva. Y así, a partir del año 2000, las inversiones, comprometen un mayor volumen de recursos pero tan sólo en tres mercados: México, Brasil (que concentran el 75\% del total de la inversión realizada entre 1993 y 2006) y, en menor medida Venezuela (véase Tabla 2). Por otra parte, Argentina que era el principal destino hasta 1998, se ha relegado dado el excesivo impacto negativo de la crisis, pasando a convertirse en una opción más residual en los últimos años. A partir de 
2005, la inversión se ha reducido en toda Latinoamérica. Cabe citar la casi inexistente inversión en Centroamérica (Costa Rica, El Salvador, Guatemala, Guayana, Haití, Honduras, Panamá). Otros países de cierta dimensión en América del Sur como Bolivia, Ecuador, Perú y Colombia han recibido una inversión reducida puesto que son economías de menor desarrollo.

Múltiples son las ventajas que justificaban esta expansión internacional de la banca española hacia el continente iberoamericano; $y$, que se basan en la coincidencia en el tiempo de dos necesidades contrapuestas y a la vez complementarias. Por una parte, a la banca española le hacia falta diversificar sus fuentes de ingresos a causa de la madurez y la competitividad alcanzadas en el mercado español. Y por otra, se produjo un cambio de estrategia en la política de desarrollo de los países latinoamericanos, caracterizada por una mayor apertura al exterior y por la desregulación y liberalización del sistema financiero, junto con otras razones que repasamos brevemente:

- La búsqueda de nuevos mercados emergentes que permitieran compensar la madurez y saturación del mercado español, y que aportarán mayores márgenes ${ }^{15}$ y crecientes beneficios, aprovechando las tendencias demográficas y de crecimiento de la renta en Latinoamérica (ventajas de localización), además de diversificar riesgos. Latinoamérica presentaba elevadas perspectivas de fuerte desarrollo (con diez veces más de población que España, Latinoamérica tiene únicamente el triple del PIB).

Por otra parte, según estudios del FMI, los ciclos económicos de la zona euro y de América Latina tienen un coeficiente de correlación muy bajo. Y esta negativa correlación favorece la diversificación en un negocio tan cíclico como el bancario (ventajas en propiedad).

- Idioma, historia y cultura comunes, factores carentes en otros posibles mercados emergentes, y que aquí, da lugar a la transferencia no solo de capital y gestión, sino de capacidades básicas y recursos humanos. El idioma es un elemento positivo que facilita el intercambio de directivos y la mejor integración de los sistemas y las personas. Los procesos de comunicación

15 Los diferenciales financieros de la banca iberoamericana, en media, se sitúan en una media de unos 8 u 9 puntos porcentuales, frente a niveles de 4 puntos en el mercado español. En América Latina son más elevados que en los países desarrollados puesto que reflejan el mayor riesgo de operar financieramente en estas economías. 
interna se facilitan, al igual que la difusión de manuales, normas, procedimientos e incluso, con las adaptaciones necesarias, los productos, servicios y las herramientas de marketing (ventajas en propiedad y de internalización).

- Privatización y liberalización de los sistemas financieros: una vez superadas las crisis bancarias y financieras que se desataron como consecuencia de la deuda externa y del posterior efecto tequila, se iniciaron procesos de privatización y liberalización del sector financiero, coincidiendo con la apertura legal y operativa hacia los flujos de inversión extranjera ${ }^{16}$ (ventajas en localización).

Las propias autoridades financieras locales alentaron la entrada de banca extranjera, justificando la misma puesto que contribuía a recapitalizar las entidades con problemas de solvencia, a introducir una mayor competencia en el sistema financiero que exigiría una mejora en la eficiencia del sector, además de permitir la introducción de nuevos productos, de nuevas técnicas de gestión bancaria y de evaluación de riesgos más sofisticadas y más modernas, apoyadas, ambas, en una tecnología más avanzada.

- Estructura bancaria: El grado de bancarización de la economía iberoamericana era bajo en su conjunto (si en España el 99\% de la personas mayores de 18 años tiene relaciones bancarias, en Latinoamérica, el ratio no superaba el $40 \%$ de media, a principios de los noventa), y además la penetración de servicios bancarios entre la población era aún muy limitada (ventajas en localización). Asimismo, la estrechez del ahorro local limitaba las necesidades de financiación que reclamaban, a mediados de los noventa, el crecimiento de las principales economías de América Latina, como las de México, Brasil, Chile, Perú y Argentina.

Por otra parte, cabe también destacar cierto atraso tecnológico en toda el área latinoamericana, la cual incide directamente en altos costes operativos y en una menor eficiencia. Esta menor

16 En Latinoamérica se ha liberalizado completamente la inversión extranjera en sectores donde antes no era posible, como es el caso del sector bancario, como indican Ruesga y Bichara (1998) con las siguientes medidas: mismo tratamiento para la inversión doméstica que la extranjera, Eliminación de controles para la repatriación de los beneficios y dividendos, Permisos para la realización de inversión directa extranjera en sectores "protegidos": banca, servicio de utilidad pública y petróleo y Creación de agencias -publicas y privadas -para la promoción y estimulo de la inversión directa extranjera en la zona. 
productividad proporciona un margen adicional, que se está consiguiendo con la inversión en tecnologías de la información, tanto para las funciones administrativas y operativas, como para los canales de distribución (ventajas en propiedad).

Otras de las carencias financieras que se observa sobre América Latina concierne al escaso y tardío desarrollo de los sistemas de previsión financiera (en un elevado número de países se ha optado por la implantación de sistemas de pensiones mixtos o privados) y de la gestión colectiva de patrimonios. Este nicho ha sido aprovechado por las entidades bancarias que estaban asentadas en dichos mercados para, y a través de su red de oficinas, promocionar gestoras propias de fondos de pensiones y de fondos de inversión (ventajas en propiedad).

- Importancia estratégica del área: el establecimiento de inversiones productivas en América Latina ha permitido a la gran banca española aumentar su dimensión (ventaja en propiedad), en previsión del establecimiento de futuros acuerdos o alianzas con bancos europeos o americanos, y también como plataforma para acceder a otros mercados, especialmente al mercado hispano de Estados Unidos.

- Escasa competencia inversora en la región: Salvo el caso de la banca americana, prácticamente ninguna otra banca ha estado interesada en la región latinoamericana (ventaja en localización). Y esta escasez de demanda, ha permitido que los precios de entrada fuesen asumibles; y mucho más baratos que en el caso europeo, como se puede apreciar en el Gráfico 1. Así, una cuota de mercado del 10 por 100 supondría unos costes casi diez veces superior en el Reino Unido que en Brasil, a pesar de ser éste último uno de los mercados más caros de Latinoamérica).

Además, la penetración de los grandes grupos financieros de los Estados Unidos (Citigroup, Fleet Boston) se ha sustentado en el establecimiento de sucursales orientadas básicamente a la actividad de banca corporativa y a los segmentos de población con rentas más elevadas. En cambio, y a pesar de que $\mathrm{SCH}$ y BBVA entran con posterioridad en la región, ofrecerán banca al por menor y realizarán una implantación masiva mediante la adquisición de participaciones de control en entidades domésticas. 
Gráfico 1: ¿Cuánto vale una franquicia?

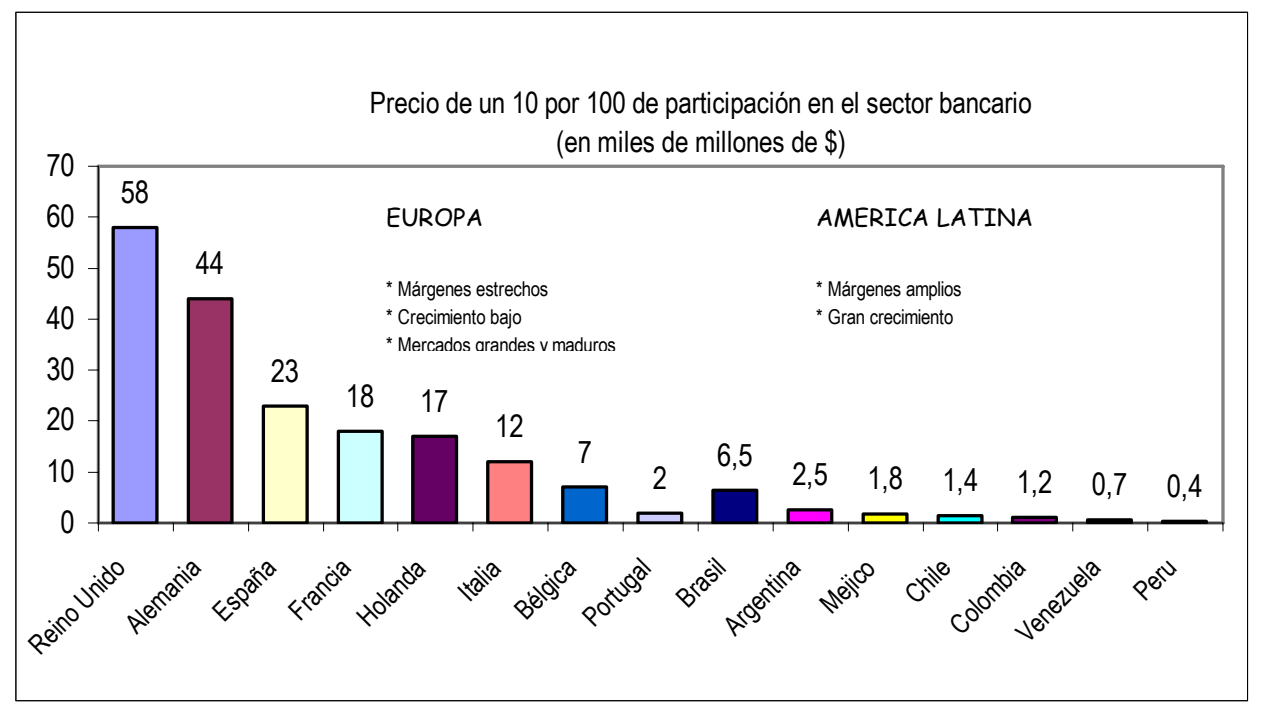

Fuente: Terreros 1999: 40.

En resumen, los grupos bancarios españoles han transnacionalizado sus operaciones en Latinoamérica con el fin de aprovechar las tres ventajas que postula el paradigma ecléctico. Obteniendo ventajas de internalización, como el control y la obtención de información directa en la relación banco-cliente, así como, la reducción de costes y la mayor flexibilidad obtenida al internacionalizar en la región, que maneja el mismo idioma y cultura similares, sus conocimientos y habilidades. Rentabilizando ventajas en propiedad, como las derivadas de trasladar sus conocimientos y habilidades a mercados menos bancarizados y más ineficientes (en tecnología y en operativa), o de obtener una mayor dimensión que diferencia con una imagen más segura al grupo, ofreciendo, además nuevas oportunidades de complementar el negocio tradicional y diversificar el riesgo. $Y$ aprovechando ventajas en la localización en un mercado con un aceptable potencial de crecimiento y con una regulación favorable, que ha contribuido a la obtención de mayores márgenes y beneficios.

Y las anteriores ventajas, además, se han podido verificar a un reducido precio. Y ello ha posibilitado, que los bancos españoles hayan asumido en esta región, de forma rápida y barata, un papel de liderazgo, tanto en actividades bancarias (préstamos y créditos) como parabancarias (gestión de fondos de inversión y fondos de pensiones), que a su vez, han 
planteado con un horizonte temporal de largo plazo. Por otra parte, los grupos bancarios constituidos no sólo están obteniendo mayores beneficios, basados en una diversificación y complementariedad del negocio de la que carecen los bancos locales; sino que además, se ha reforzado su dimensión bancaria. Fortalecimiento del tamaño, que no sólo ha consolidado la posición competitiva de las entidades resultantes en sus mercados de actuación, sino que además, ha permitido a los grupos BBVA y Banco Santander, en el nuevo siglo XXI, acometer inversiones que precisaban un compromiso de elevado volumen de recursos en otros mercados comunitarios y estadounidenses.

Por otra parte, la implantación en Iberoamérica de la gran banca española se ha producido en base a una estrategia gradual. En la etapa previa, desarrollaron formulas contractuales poco costosas que las ha permitido acumular experiencia respecto del mercado local. $Y$ ahora, en la década de los noventa, los bancos han desarrollado su internacionalización comprometiendo mucha mas inversión y asumiendo un mayor riesgo (fusiones, adquisiciones de participaciones, etc.).

En esta década, los bancos han aplicado su tradicional línea de gestión, ofertándose como banca universal, al por menor, y amparándose en un amplio crecimiento externo que ha pasado por la integración o adquisiciones de participaciones mayoritarias de bancos locales, que han permitido gestionar directamente el trato directo con el cliente e internalizarlo mediante la IDE, como la mejor vía que aprovecha las características diferenciadoras de los servicios ${ }^{17}$ financieros (como indican Vandermerwe y Chadwick 1989) ofrecidos transnacionalmente por la gran banca. En los últimos años, además han combinado su oferta universal con la especialización en la gestión de fondos de pensiones privados y en la administración de fondos de inversión.

Han aplicado una estrategia ofensiva en su diversificación geográfica en América Latina, por varias razones. En primer lugar, porque el estilo de banca que han implementado en su internacionalización se corresponde principalmente con la banca al por menor. $Y$ este tipo de banca exige el establecimiento de oficinas, medios electrónicos, etc., en

17 Con la banca al por menor (la banca dirigida fundamentalmente a las economías domésticas y a las pequeñas y medianas empresas) resulta conveniente el establecimiento de una amplia red de oficinas y medios electrónicos en los países en los que se opera, lo cual implica la presencia física mediante la creación de sucursales y filiales, etc. 
los países en los que se opera, lo cual supone crear filiales, sucursales, etc., en dichas localizaciones. $Y$ esto es exigido puesto que los servicios de banca al por menor no pueden ser almacenados o transportados ya que son producidos en contacto directo con el cliente, teniendo lugar de forma simultánea la producción y el consumo de los mismos.

El grupo SCH consolidó su posicionamiento en América Latina en la década de los noventa. Antes de la fusión Santander-Central Hispano (1999), ambas entidades habían realizado inversiones en las principales economías latinoamericanas. El Santander había fusionado y adquiridos bancos locales, que pasaría a gestionar aplicando un modelo de banca universal, especialmente a partir de 1995 (se desarrolla el negocio en Argentina, Brasil, Colombia, México, Perú y Venezuela, al tiempo que se da un nuevo impulso a negocios ya existentes en Chile, Puerto Rico y Uruguay). Por otra parte, el antiguo Banco Central Hispanoamericano consolidaba su presencia en Latinoamérica, a diferencia del BBV y B. Santander, a través de la constitución de un gran holding inversor, la sociedad O'Higgins Central Hispano $(\mathrm{OMCH})$, en colaboración con el grupo chileno Luksic, acuerdo que se rompió con la fusión y creación del BSCH. Esta estrategia, diferente de la del BBVA y Santander, intentaba aprovechar la red de oficinas existentes y la no intervención en la gestión.

Y al finalizar el año 2000, después sus adquisiciones en el mercado brasileño (Banespa y Grupo Meridional que le permitieron aumentar su cuota en dicho mercado en un 341,5\%) y mexicano (con la adquisición de Banco Serfin), así como el Banco Santiago en Chile, el grupo BSCH se había convertido en un líder en Latinoamérica, siendo la primera franquicia regional de servicios financieros, que contaba con una sólida presencia en once países, gestionando dieciséis bancos, en los que trabajaban 72.241 empleados repartidos en 4.638 oficinas a lo largo del continente. En su fortalecimiento había llegado a captar el 10,3\% de los depósitos latinoamericanos, y por otra parte, aumentar su inversión crediticia, puesto que al final del año 2000, ofrecía el 9,9\% de los créditos latinoamericanos. Con ello, la aportación del área a su margen de intermediación se cifro, en el año 2000, en un 50,34\% del margen obtenido por el grupo en su conjunto, además de aportar el $43 \%$ de los beneficios totales.

Ahora bien, aunque su presencia abarca la mayor parte de los países iberoamericanos, su esfuerzo inversor se ha concentrado en los que por tamaño, potencial de negocio, riesgo y capacidad de gestión podrían generar al banco mayores retornos. De los 15.700 millones de dólares 
invertidos en el área hasta el año 2001, el 74\% se había concentrado en México, Brasil, Chile y Puerto Rico.

El grupo BBVA, si bien, inicio con retraso frente al $\mathrm{SCH}$ su expansión por Latinoamérica, la dinámica inversora desarrollada en los noventa ha sido determinante para convertirse en uno de los principales grupos bancarios de la región (véase Tabla 3 ).

$A$ pesar de la escasa experiencia en el mercado, el BBVA aplicó estrategias de crecimiento externo por medio de adquisiciones de paquetes de control mayoritarios de entidades locales, con el fin de hacerse con la gestión de las mismas. Con ello el grupo BBV consiguió una rápida expansión utilizando el conocimiento y experiencia del socio local. Sería a partir de 1995 cuando desarrolla esta acelerada estrategia de expansión internacional que le llevó a construir una gran franquicia en América Latina, realizando una importante inversión en capital, tecnología y recursos humanos. En 1995, entre en Perú con la privatización del Banco Continental y en México con Probursa. En 1996, amplia su presencia en Colombia con Banco Ganadero y en Argentina con el Banco Francés. En 1997, BBVA entra en Venezuela de la mano de Banco provincial. En 1988, se instala en Chile con el Banco BHIF. Y finalmente, en el año 2000, se produce en México la fusión del BBVA Probursa con Bancomer para crear BBVA Bancomer, el primer banco en dicho país.

Al finalizar el año 2000, BBVA estaba operando en once países del área y tenía comprometido el $36,46 \%$ de su activo en Iberoamérica. Esta elevada cifra implicaba la gestión de activos por un valor que superaba los 10,81 miles de millones de euros y una base de 20 millones de clientes. La cuota de mercado del BBVA en América Latina era del 11 por 100 en depósitos, elevándose al 28 por 100 en fondos gestionados en pensiones (véase Tabla 3). Los activos de BBVA América representaban el 21 por 100 de los activos de BBVA y aportaban un 19 por 100 de los beneficios. Esta gran franquicia financiera se asentaba en una red de 4.865 oficinas bancarias y una plantilla de 72.314 empleados (el 66,91\% del grupo bancario).

Con la constitución de los grupos bancarios BBVA y BSCH se consolidó su expansión internacional en el área de la banca comercial, como hemos comentado. Sin embargo, también detectaron, con su implantación en los mercados locales, el escaso desarrollo de la gestión de patrimonios colectivos y de fondos de previsión. Por ello, realizaron ambos amplias tomas de participación en gestoras de fondos de inversión y de pensiones 
en la mayoría de los países latinoamericanos, llegando a liderar y controlar, al final del 2000, entre el BBVA y el BSCH, el $42,9 \%$ del mercado latinoamericano de fondos de pensiones. Desglosando dicha cifra, se observa que el patrimonio en fondos de pensiones gestionado por BBVA $(28,5 \%)$ era superior al que gestionaba el $B S C H(14,4 \%)$. Esta mayor presencia del BBVA tiene su origen en las posiciones que Argentaria, antes de la fusión, ya tenía comprometidas en la gestión de fondos de pensiones en el área latinoamericana; y que una vez fusionado el grupo ha reforzado notablemente. $Y$ de esta forma, el BBVA en Latinoamérica gestionaba al final del año 2000 un patrimonio superior a 4,7 billones de pesetas, pertenecientes a más del 9,6 millones de afiliados. En cuanto al mercado de fondos de inversión, las posiciones del BSCH eran muy superiores a las del BBVA, puesto que al final del año 2000 gestionaba 12.213 millones de euros, mientras que, las gestoras del BBVA solamente gestionaban 8.414 millones de euros.

Tabla 3: Posición de mercado por países de América Latina para el grupo BBVA

\begin{tabular}{|c|c|c|c|c|c|c|c|c|c|c|c|c|}
\hline \multirow[b]{3}{*}{ Países } & \multicolumn{4}{|c|}{ Depósitos } & \multicolumn{4}{|c|}{ Créditos } & \multicolumn{4}{|c|}{ Pensiones } \\
\hline & \multicolumn{2}{|c|}{ Cuota (\%) } & \multicolumn{2}{|c|}{ Ranking } & \multicolumn{2}{|c|}{ Cuota (\%) } & \multicolumn{2}{|c|}{ Ranking } & \multicolumn{2}{|c|}{ Cuota (\%) } & \multicolumn{2}{|c|}{ Ranking } \\
\hline & 2000 & 2006 & 2000 & 2006 & 2000 & 2006 & 2000 & 2006 & 2000 & 2006 & 2000 & 2006 \\
\hline Argentina & 9,2 & 9,5 & $2^{\circ}$ & $1^{\mathrm{o}}$ & 6.9 & 7,6 & $2^{\circ}$ & $2^{\circ}$ & 19.5 & 18,5 & $2^{\circ}$ & $2^{\circ}$ \\
\hline Chile & 5,3 & 7,9 & $6^{\circ}$ & $4^{\circ}$ & 5.5 & 8,8 & $6^{\circ}$ & $4^{\circ}$ & 31.8 & 30,7 & $1^{\circ}$ & $1^{\circ}$ \\
\hline Colombia & 7,3 & 11,7 & $3^{\circ}$ & $4^{\circ}$ & 7.5 & 11,5 & $3^{\circ}$ & $4^{\circ}$ & 24.6 & 17,2 & $1^{\circ}$ & $1^{\circ}$ \\
\hline México & 30,4 & 26,0 & $1^{\circ}$ & $1^{\circ}$ & 29.4 & 30,0 & $1^{\mathrm{o}}$ & $1^{\circ}$ & 22.8 & 19,2 & $1^{\circ}$ & $2^{\circ}$ \\
\hline Perú & 19,0 & 24,7 & $3^{\circ}$ & $2^{\circ}$ & 13.6 & 27,4 & $3^{\circ}$ & $2^{\circ}$ & 25.2 & 23,7 & $3^{\circ}$ & $2^{\circ}$ \\
\hline Venezuela & 18,4 & 9,7 & $2^{\circ}$ & $4^{\circ}$ & 17.9 & 11,8 & $3^{\circ}$ & $4^{\circ}$ & ---- & --- & --- & -- \\
\hline
\end{tabular}

Elaboración propia en base a los datos extraídos de los Informes Anuales del grupo BBVA. Años 2000 y 2006.

\section{2.c. Internacionalización hacia Europa}

La expansión a Europa, con mercados maduros y posibilidades de adquisiciones escasas y de alto precio, ha requerido fórmulas que se salen de lo convencional, que básicamente se han concretado en un crecimiento externo, basado en el establecimiento de acuerdos de cooperación y alianzas estratégicas con otras entidades europeas, mediante un intercambio accionarial, la presencia en los consejos de administración y la colaboración en negocios específicos La euroestrategia de la gran banca española ha tenido un carácter selectivo y defensivo. Selectivo en el sentido de que se han escogido mercados físicamente próximos y plazas 
financieras fundamentales de Europa Occidental (Reino Unido, Alemania). Y por otra parte, se ha aplicado una estrategia defensiva (salvo en el caso de Portugal) puesto que se ha tratado no sólo de evitar posibles compras o combinaciones de empresas no deseadas sino también de afianzar la posición de la gran banca en el mercado español.

Tabla 4: Inversión de la banca española en la UE-25

\begin{tabular}{|l|r|r|r|r|}
\hline \multirow{2}{*}{ Países } & \multicolumn{1}{|c|}{$\mathbf{1 9 9 3 - 2 0 0 0}$} & \multicolumn{1}{|c|}{$\mathbf{2 0 0 1 - 2 0 0 6}$} & \multicolumn{2}{|c|}{$\mathbf{1 9 9 3 - 2 0 0 6}$} \\
\cline { 2 - 5 } & Millones $\boldsymbol{\epsilon}$ & \multicolumn{1}{c|}{ Millones $\boldsymbol{\epsilon}$} & \multicolumn{1}{c|}{ Millones $\boldsymbol{€}$} & \multicolumn{1}{c|}{$\mathbf{0}$} \\
\hline ALEMANIA & $\mathbf{1 . 1 6 1 , 6 5}$ & $\mathbf{2 . 0 3 2 , 4 3}$ & $\mathbf{3 . 1 9 4 , 0 8}$ & $\mathbf{1 1 , 9 9}$ \\
\hline BÉLGICA & 77,87 & 900,00 & 977,87 & 3,67 \\
\hline FRANCIA & 454,30 & 303,62 & 757,92 & 2,84 \\
\hline IRLANDA & 194,64 & 0,10 & 194,74 & 0,73 \\
\hline ITALIA & 546,48 & 380,63 & 927,11 & 3,48 \\
\hline LUXEMBURGO & 171,79 & 331,41 & 503,20 & 1,89 \\
\hline PAÍSES BAJOS & $\mathbf{1 . 2 3 6 , 3 4}$ & $\mathbf{4 0 9 , 6 9}$ & $\mathbf{1 . 6 4 6 , 0 2}$ & $\mathbf{6 , 1 8}$ \\
\hline PORTUGAL & $\mathbf{4 . 4 3 5 , 8 9}$ & $\mathbf{7 2 0 , 5 0}$ & $\mathbf{5 . 1 5 6 , 3 9}$ & $\mathbf{1 9 , 3 5}$ \\
\hline REINO UNIDO & $\mathbf{1 8 6 , 9 1}$ & $\mathbf{1 2 . 9 4 2 , 5 3}$ & $\mathbf{1 3 . 1 2 9 , 4 4}$ & $\mathbf{4 9 , 2 7}$ \\
\hline SUECIA & 0,40 & 2,44 & 2,84 & 0,01 \\
\hline POLONIA & 0,00 & 158,56 & 158,56 & 0,60 \\
\hline & $\mathbf{8 . 4 6 6 , 2 7}$ & $\mathbf{1 8 . 1 8 1 , 9 1}$ & $\mathbf{2 6 . 6 4 8 , 1 8}$ & $\mathbf{1 0 0 , 0 0}$ \\
\hline
\end{tabular}

Elaboración propia en base a los datos Dirección General de Comercio e Inversiones Exteriores.

La inversión bruta realizada por la banca y otros intermediarios financieros en la Europa comunitaria, entre 1993 y el año 2000 , implicaba casi un tercio $(28,75 \%$ como se recoge en la Tabla 1$)$ de la invertida internacionalmente por la banca española (véase Tabla 2), al cifrarse en 8.466,27 millones de euros, de los que es principal protagonista la gran banca. Esta inversión importante, pero de menor impacto que la realizada en el mismo período sobre Latinoamérica, se destino, principalmente, hacia el próximo mercado de Portugal y, también se asentó en los principales centros financieros de la Unión Europea Occidental (véase Tabla 4).

Los 4.435,89 millones de euros destinados al mercado portugués entre 1993 y el año 2000, se han correspondido con la principal inversión realizada en el país vecino por la banca y los intermediarios financieros en las tres últimas décadas (supuso el $52 \%$ de la inversión realizada en dicha década). El reducido coste de adquisición de cuota, frente al resto de plazas europeas (véase Tabla 1), animó a la banca española a aplicar una estrategia ofensiva, basada en un crecimiento externo, en el 
que primaron la adquisición de entidades lusas en el caso del Santander, pero también con un crecimiento interno, a través de la apertura de sucursales por parte del BBVA.

Cuadro 2: Implantación significativa de BBVA y BSCH en Europa, 2000

\begin{tabular}{|l|l|l|}
\hline Países & BBVA & BSCH \\
\hline FRANCIA & Crédit Lyonnais (3'75\%) & Société Générale (7\%) \\
\hline BÉLGICA & & BCH Benelux \\
\hline REINO UNIDO & & Royal Bank of Scotland $(9,6 \%)$ \\
\hline ALEMANIA & BBV Deutschland & $\begin{array}{l}\text { Commerzbank }(4,7 \%) \\
\text { Santander Direkt Bank (100\%) } \\
\text { CCBank (100\%) }\end{array}$ \\
\hline ITALIA & Banca Nazionale del Lavoro $(10 \%)$ & $\begin{array}{l}\text { San Paolo IMI }(7 \%) \\
\text { Finconsumo }(50 \%)\end{array}$ \\
\hline PORTUGAL & BBV Portugal (100\%) & $\begin{array}{l}\text { BSN Portugal }(81,64 \%) \\
\text { Banco Totta y Acores }(100 \%) \\
\text { Crédito Predial }(99,20 \%) \\
\text { Banco Madesant }(100 \%)\end{array}$ \\
\hline GIBRALTAR & $\begin{array}{l}\text { BBV Privanza Gibraltar } \\
\text { BBV Privanza International Gibraltar }\end{array}$ & $\begin{array}{l}\text { BSCH Commerzbank Gibraltar } \\
\text { Royal Bank of Scotland Gibraltar }\end{array}$ \\
\hline
\end{tabular}

Elaboración propia en base a los Informes Anuales del grupo BBVA y del grupo Santander.

Por otra parte, la inversión en centros financieros la realizó la banca con el fin de obtener economías de aglomeración y así explotar ventajas en la localización en mercados desarrollados que además, desde 1993 compartían normas comunes en materia bancaria y de capitales. Así, en este período las inversiones en Alemania y Países Bajos se realizaron por un valor de 2.397,99 millones de euros (véase Tabla 4). Dicha inversión, dado el coste de entrada en dichos mercados se pacto básicamente con la firma de acuerdos de colaboración. Veamos ahora que ocurre con la gran banca española.

El grupo Santander, al final del año 2000, estaba entre los primeros bancos de la zona euro por activos y recursos propios (véase Cuadro 2). Esta privilegiada posición le había permitido formalizar y consolidar cuatro alianzas estratégicas con fuertes grupos europeos (Royal Bank of Scotland, Société Générale, San Paolo-IMI y Commerzbank), asentándose en cuatro mercados principales (Reino Unido, Francia, Italia, Alemania). Por otra parte, en 1993 entra en Portugal de la mano del $\mathrm{BCl}$, y consolida la misma con la adquisición del Banco Totta y Banco Predial, llegando a detentar, a finales del 2000, una cuota de más del $10 \%$ en banca comercial en el mercado portugués. 
Cuadro 3: Estrategias de internacionalización de la gran banca española $2^{\text {a }}$ Etapa: Impulso a la internacionalización (1992-2000)

\begin{tabular}{|c|c|c|c|}
\hline Criterios & Latinoamérica & Europa (CEE-12) & Paraísos fiscales y EE.UU. \\
\hline Estrategia & Estrategia ofensiva y gradual & $\begin{array}{l}\text { Estrategia defensiva y Oportu- } \\
\text { nista (plazas principales), y ofen- } \\
\text { siva (Portugal) }\end{array}$ & Ofensiva y gradual \\
\hline Actividad & $\begin{array}{l}\text { Bancaria y parabancaria (gestión } \\
\text { y administración de fondos de } \\
\text { pensiones y de inversión) }\end{array}$ & \multicolumn{2}{|l|}{ Bancaria } \\
\hline $\begin{array}{l}\text { Métodos de } \\
\text { entrada }\end{array}$ & $\begin{array}{l}\text { Elevado compromiso de recursos } \\
\text { y riesgos: } \\
\text { - Crecimiento interno (apertura } \\
\text { de sucursales) } \\
\text { - Notable crecimiento externo } \\
\text { (alianzas, fusiones y adquisi- } \\
\text { ciones, participaciones mayo- } \\
\text { ritarias) }\end{array}$ & \begin{tabular}{|l|} 
Moderado compromiso en \\
recursos: \\
- Crecimiento interno (apertura \\
de sucursales -Portugal-) \\
- Crecimiento externo (acuerdos \\
y alianzas en principales \\
mercados)
\end{tabular} & $\begin{array}{l}\text { Escaso compromiso } \\
\text { (Crecimiento externo) }\end{array}$ \\
\hline Motivaciones & $\begin{array}{l}\text { Ventajas en localización } \\
\text { (mercados emergentes con } \\
\text { potencial de crecimiento y } \\
\text { regulación favorable, apro- } \\
\text { vechamiento de márgenes y } \\
\text { beneficios, etc.) } \\
\text { - Ventajas en propiedad (dife- } \\
\text { renciación del grupo bancario, } \\
\text { obtención de mayor dimensión } \\
\text { bancaria, diversificación del } \\
\text { riesgo al trabajar en regiones } \\
\text { con diferente grado de corre- } \\
\text { lación en sus ciclos econó- } \\
\text { micos, complementariedad del } \\
\text { negocio, traslado de cono- } \\
\text { cimientos y habilidades a } \\
\text { mercados menos bancari- } \\
\text { zados y atrasados tecnológi- } \\
\text { camente, etc.) } \\
\text { Ventajas internalización } \\
\text { (reducción de costes y mayor } \\
\text { flexibilidad en la implemen- } \\
\text { tación de conocimientos y } \\
\text { habilidades en el mercado } \\
\text { "cercano" de Latinoamérica, } \\
\text { banca al por menor en la que } \\
\text { resulta vital controlar direc- } \\
\text { tamente el flujo de infor- } \\
\text { mación con el cliente, etc.) } \\
\text { Inversión en mercados } \\
\text { cercanos "psíquicamente" }\end{array}$ & $\begin{array}{l}\text { - Ventajas localización (apro- } \\
\text { vechamiento de las ventajas } \\
\text { del mercado único, econo- } \\
\text { mías de aglomeración, etc.) } \\
\text { - Ventajas en propiedad (dife- } \\
\text { renciación de la entidad como } \\
\text { grupo comunitario, comple- } \\
\text { mentariedad del negocio y } \\
\text { ampliar conocimiento sobre } \\
\text { los socios y mercados) } \\
\text { - Ventajas de internalización } \\
\text { (seguimiento al cliente, etc.) } \\
\text { - Inversión en mercados cercano } \\
\text { físicamente. }\end{array}$ & $\begin{array}{l}\text { Ventajas localización (regu- } \\
\text { lación y dimensión del mercado) }\end{array}$ \\
\hline
\end{tabular}

Por otra parte, el grupo BBVA, también buscó los mercados próximos del sur de Europa, para ampliar su dimensión comunitaria. En Francia e Italia suscribió alianzas estratégicas con dos importantes grupos bancarios nacionales (Banca Nazionale del Lavoro, Crédit Lyonnais), mientras 
en Alemania abrió una oficina de representación. Sin embargo, y al igual que el $\mathrm{SCH}$, la gran apuesta europea de BBVA se centro en Portugal, por proximidad y por coste, y en este caso si que realizó inversión directa en base a un crecimiento interno (apertura de sucursales), llegando a tener a finales del año 2000, 115 oficinas operativas.

A parte de estas principales inversiones, ambos grupos, con especial incidencia del BBVA, han realizado inversiones transnacionales en paraísos fiscales europeos, como es el caso de Gibraltar y, en cierta medida, Andorra, respondiendo a la ventaja de internalizar la menor regulación de que gozan sus mercados destino.

En el resto (América, Asia y África), la presencia del BBVA y Santander se limitaba a sucursales y oficinas de representación, lo que indicaba que en los mercados desconocidos para dichas entidades preferían aplicar procedimientos de menor riesgo y coste.

$3^{a}$ ETAPA: Consolidación y reforzamiento de una internacionalización, operativa y geográficamente, más selectiva

El nuevo siglo trae un nuevo contexto competitivo en los dos mercados principales de inversión de la banca española. Por una parte, en Europa, la consecución de una Unión Económica y Monetaria Europea (UEME), no sólo aportó un envidiable marco de estabilidad macroeconómica, sino que también tuvo un considerable efecto dinamizador como consecuencia de la reducción de costes, la desaparición del riesgo de cambio intrazona que han venido generando una mayor transparencia de precios y el avance hacia un mercado de capitales más líquido y profundo. Por otra parte, en Latinoamérica se ha producido un deterioro de la situación y de las perspectivas económicas sobre la región; a lo que hay que añadir que el proceso privatizador, emprendido por los países del área en los noventa, empieza a estar agotado. A este contexto ya no tan favorable hay que sumarle la posición dominante que la banca española ha alcanzado en una buena parte de los países, no dejando, por tanto, mucho más espacio para nuevas operaciones.

En consecuencia, el nuevo contexto determinará que la banca española, y en especial los grandes protagonistas de esta expansión, el grupo BBVA y el grupo Santander, hayan modificado el destino de sus inversiones internacionales. De forma, que las nuevas inversiones transnacionales se han dirigido mayoritariamente hacia Europa y los países desarrollados, 
con especial incidencia en Estados Unidos, aunque, dentro de América Latina, se han dirigido puntuales e intensos flujos de forma selectiva. Así, entre 2001 y 2006 , el $92,25 \%$ del total de una elevada inversión, cifrada en 29.278,94 millones de euros se ha destinado a los países OCDE (véase Tabla 1). El $56,79 \%$ de las inversiones totales transfronterizas aterrizaron en la Europa comunitaria occidental. Mientras que la entrada de los países del este en la Unión Europea no han modificado las expectativas de la gran banca española puesto que ha corregido ligerísimamente el porcentaje de la UE-15 $(56,79 \%)$ con el de la UE-25 (57,29\%). Y en menor medida, pero con un notable crecimiento respecto del período anterior, las inversiones destinadas a Estados Unidos (20,22\%). En cambio, las inversiones en América Latina se han rebajado en volumen (se han reducido a la mitad, al pasar de 13 mil millones en la segunda etapa a 6 mil millones en los últimos años, y han pasado a representar tan sólo el $19,74 \%$ del total de la elevada inversión realizada entre 2001-2006), y se han concretado básicamente en torno a tres mercados (Brasil, México y Venezuela).

Tabla 5: Principales países en la recepción de inversión transnacional realizada por la banca y los intermediarios financieros españoles, 1993-2006

\begin{tabular}{|llrc|}
\hline \multirow{2}{*}{ Ranking } & Países & \multicolumn{2}{c|}{$\mathbf{1 9 9 3 - 2 0 0 6}$} \\
\cline { 3 - 4 } & & millones euros & \% respecto total \\
\hline 1 & Reino Unido & $13.130,96$ & 20,95 \\
\hline 2 & EE.UU & $11.196,05$ & 17,86 \\
\hline 3 & México & $7.387,07$ & 11,78 \\
\hline 4 & Brasil & $7.187,47$ & 11,47 \\
\hline 5 & Portugal & $5.168,71$ & 8,24 \\
\hline 6 & Alemania & $3.228,08$ & 5,15 \\
\hline 7 & Venezuela & $1.687,93$ & 2,69 \\
\hline 8 & Países Bajos & $1.646,02$ & 2,63 \\
\hline 9 & Argentina & $1.395,78$ & 2,23 \\
\hline 10 & Suiza & $1.187,25$ & 1,89 \\
\hline & Resto de países & $9.473,82$ & 15,11 \\
\cline { 2 - 4 } & & $53.215,62$ & 84,89 \\
\cline { 2 - 4 } & & $62.689,14$ & 100,00 \\
\hline
\end{tabular}

Fuente: Dirección General de Comercio e Inversiones Exteriores Elaboración propia.

Por otra parte, la inversión en el resto de los continentes resulta escasa y esporádica en el caso de Asia (0,33\% del total entre 1993 y 2006) y muy limitada en el de África $(0,03 \%$ del total para el mismo período, la cual se ha centrado en Túnez, Egipto y Marruecos). Aunque, también cabe citar el reciente interés que está suscitando China en la 
estrategia internacional del grupo BBVA, las cuales han representando el 42,21\% de las inversiones pactadas en el primer semestre de 2007.

Al finalizar el año 2006, se confirma una elevada concentración en el destino de la inversión transnacional de la banca española en torno a la Unión Europea, Latinoamérica y EE.UU. (véase Tabla 5). Concretamente, en cinco países se concentra el $70 \%$ de los riesgos y recursos totales comprometidos por los bancos españoles en catorce años de expansión internacional (Tabla 6). Destaca especialmente el Reino Unido, donde se realizó por parte del Banco Santander una de las operaciones bancarias más importantes de los últimos tiempos en el contexto mundial. En la vecina Portugal, tanto el BBVA como el Santander han realizado una importante inversión, a pesar de la pequeña dimensión de dicho mercado. En EE.UU., el BBVA ha tomado posiciones en torno al mercado hispano y al sur de los Estados Unidos. Dentro de Latinoamérica, las inversiones se han incrementando en torno a los países que mejor resolvieron sus crisis financieras y económicas de los noventa y están presentando crecimientos notables, México y Brasil. En Brasil el Banco de Santander ha realizado una fuerte apuesta, mientras en México la ha realizado el BBVA.

En el nuevo siglo, y a diferencia de las primeras incursiones en otros países desarrollados en los que la entrada se había realizado basándose en una estrategia defensiva, ahora la estrategia es ofensiva (véase Cuadro 4). En la eurozona, el grupo Santander ha optado por métodos de entrada que implican un crecimiento externo, plasmándose en importantes adquisiciones mayoritarias y alianzas transfronterizas, que han tenido por objeto introducirse de forma firme en fuerte plazas financieras comunitarias, en la actividad de banca comercial y de financiación al consumo. En Estados Unidos, el BBVA, como principal inversor, también ha practicado una intensa estrategia ofensiva que se ha basado en un sobresaliente crecimiento externo, mediante las compras mayoritarias de paquetes accionariales de bancos estadounidenses. En ambos casos, estas inversiones recogen decisiones graduales de incrementar la actividad internacional por ambos bancos.

La estrategia seguida en la América Latina se ha plasmado también en adquisiciones mayoritarias de empresas ya existentes, lo que ha supuesto decisiones de crecimiento externo, tanto para el Santander como para el BBVA (véase Cuadro 4). Decisiones de carácter ofensivo que buscan incrementar la cuota en el mercado local. Estas actuaciones también 
recogen el carácter gradual de la internacionalización por ambas entidades en el área.

Cuadro 4: Estrategias de internacionalización de la gran banca española $3^{\text {a }}$ Etapa (2001-2006): Consolidación y reforzamiento de una internacionalización operativa y geográficamente más selectiva

\begin{tabular}{|c|c|c|c|}
\hline Criterios & Latinoamérica & Europa (CEE-12) & EE.UU. \\
\hline Estrategia & Ofensiva y gradual & & $\begin{array}{l}\text { Gradual (BBVA) y Oportunista } \\
\text { (Santander) }\end{array}$ \\
\hline Actividad & $\begin{array}{l}\text { Bancaria (comercial y banca } \\
\text { privada) } \\
\text { Parabancaria (gestión y adminis- } \\
\text { tración de fondos de pensiones y } \\
\text { de fondos de inversión, seguros) }\end{array}$ & $\begin{array}{l}\text { Bancaria (comercial, banca } \\
\text { privada y mayorista) } \\
\text { Parabancaria (Seguros y Finan- } \\
\text { ciación al consumo -Santander-) }\end{array}$ & $\begin{array}{l}\text { Bancaria (comercial y privada) } \\
\text { Parabancaria (financiación al } \\
\text { consumo) }\end{array}$ \\
\hline $\begin{array}{l}\text { Métodos de } \\
\text { entrada }\end{array}$ & $\begin{array}{l}\text { Elevado compromiso de recursos } \\
\text { y riesgos realizado de forma } \\
\text { selectiva por países y negocios } \\
\text { - Notable crecimiento externo } \\
\text { (adquisiciones, participaciones } \\
\text { mayoritarias) }\end{array}$ & $\begin{array}{l}\text { Compromiso de recursos y } \\
\text { riesgos sobresaliente (B. } \\
\text { Santander) y escaso (BBVA) } \\
\text { - Notable crecimiento externo } \\
\text { (alianzas y toma participa- } \\
\text { ciones mayoritarias y adqui- } \\
\text { siciones) }\end{array}$ & $\begin{array}{l}\text { Elevado compromiso por parte } \\
\text { del BBVA y escaso en el caso } \\
\text { del grupo Santander } \\
\text { (Crecimiento externo) }\end{array}$ \\
\hline & $\begin{array}{l}\text { - Ventajas en localización } \\
\text { (mercados emergentes con } \\
\text { potencial de crecimiento y en } \\
\text { proceso de bancarización, } \\
\text { etc.) } \\
\text { - Ventajas en propiedad (dife- } \\
\text { renciación del grupo bancario } \\
\text { por ser líder, liderazgo por } \\
\text { actividades, aumentar dimen- } \\
\text { sión bancaria, complemen- } \\
\text { tariedad del negocio, diversi- } \\
\text { ficación del riesgo) } \\
\text { - Ventajas internalización (banca } \\
\text { al por menor en la que resulta } \\
\text { vital controlar directamente el } \\
\text { flujo de información con el } \\
\text { cliente, etc.) } \\
\text { - Inversión en mercados cercanos } \\
\text { "psíquicamente" }\end{array}$ & $\begin{array}{l}\text { - Ventajas localización (apro- } \\
\text { vechamiento de las ventajas } \\
\text { del mercado único, econo- } \\
\text { mías de aglomeración) } \\
\text { - Ventajas en propiedad (dife- } \\
\text { renciación de la entidad como } \\
\text { grupo comunitario y global } \\
\text { complementariedad del } \\
\text { negocio, liderazgo por } \\
\text { segmentos, aumentar } \\
\text { dimensión bancaria, comple- } \\
\text { mentariedad negocio) } \\
\text { - Ventajas de internalización } \\
\text { (ofrecimiento de banca } \\
\text { comercial al por menor, etc.) } \\
\text { - Inversión en mercados cercanos } \\
\text { físicamente. }\end{array}$ & $\begin{array}{l}\text { - Ventajas localización: (dimen- } \\
\text { sión e importancia del } \\
\text { mercado) } \\
\text { - Ventajas en propiedad } \\
\text { (aumentar dimensión bancaria, } \\
\text { diferenciación de la entidad, } \\
\text { diversificación del riesgo) } \\
\text { - Ventajas de internalización } \\
\text { (seguimiento del cliente, ofre- } \\
\text { cimiento de banca al por } \\
\text { menor) }\end{array}$ \\
\hline
\end{tabular}

Elaboración propia.

En este nuevo siglo, siguen vigentes la prioridad de la cercanía física y "psíquica", y el carácter incremental en las decisiones de internacionalización, que postulaban la escuela de Uppsala, al observar las principales inversiones transnacionales realizadas por BBVA y Santander. Y también, en esta etapa se puede seguir explicando las decisiones internacionales de ambas entidades en base a la teoría ecléctica, en la que han cobrado una singular importancia ciertas ventajas en propiedad, 
como la búsqueda de una mayor dimensión bancaria y de una mayor liderazgo en determinadas áreas geográficas (como es el caso de Latinoamérica en la que ambos bancos son entidades lideres en banca comercial y pensiones), y en la implantación de actividades bancarias o de complementar el negocio con la introducción de actividades parabancarias (financiación al consumo en el caso del grupo Santander o de gestión de pensiones en Latinoamérica en el de BBVA, seguros en ambos casos, etc.). A su vez, la diversificación de la red de oficinas contribuye en ambos grupos a diversificar el riesgo de inversión y a diversificar el origen de los beneficios, en u negocio tan cíclico como el bancario.

Cuadro 5: Presencia internacional de la Gran Banca Española (31/12/2006)

\begin{tabular}{|c|c|c|}
\hline \multicolumn{3}{|c|}{ Bancos filiales y sucursales de bancos españoles en el extranjero } \\
\hline \multicolumn{2}{|c|}{ EUROPA } & \multirow[t]{2}{*}{ AMÉRICA LATINA } \\
\hline UNIÓN EUROPEA & RESTO EUROPA & \\
\hline$\frac{\mathbf{S C H}}{\text { Alemania, Italia, Portugal) }}$ & $\begin{array}{l}\frac{\text { BBVA (Andorra, Suiza, Gibraltar y }}{\text { Channel Islands) }} \\
\frac{\text { SCH }}{\text { Hungría) }}\end{array}$ & $\begin{array}{l}\text { BBVA (Argentina, Brasil, Chile, } \\
\text { Colombia, México, Panamá, } \\
\text { Paraguay, Perú, Puerto Rico, } \\
\text { Uruguay, Venezuela) } \\
\text { SCH (Argentina, Brasil, Bolivia, Chile, } \\
\text { Colombia, México, Paraguay, } \\
\text { Uruguay, Venezuela, Puerto Rico, } \\
\text { Panamá ) }\end{array}$ \\
\hline \multicolumn{3}{|c|}{$\begin{array}{l}\text { RESTO DEL MUNDO } \\
\text { BBVA (Islas Caimán, Antillas Holandesas, EE.UU., Japón) } \\
\text { SCH (EE.UU., Malasia, Bahamas, Marruecos, Mozambique, Angola) }\end{array}$} \\
\hline \multicolumn{3}{|c|}{ Oficinas de Representaciones en el extranjero } \\
\hline $\begin{array}{l}\text { BBVA (Alemania, Rusia, Suiza, Cu } \\
\text { SCH (el Salvador, Guatemala, Rep }\end{array}$ & $\begin{array}{l}\text { a, Irán, China) } \\
\text { blica Dominicana, Perú, Irán, Japón }\end{array}$ & ina y Australia) \\
\hline
\end{tabular}

Elaboración propia según memorias de principales grupos bancarios españoles.

Ahora, exponemos los aspectos principales en las recientes y sobresalientes decisiones de internacionalización de la gran banca española. Desde el año 2000, el Santander ha diversificado geográfica y operativamente su estrategia de expansión internacional, en línea con los cambios de contexto que se han mencionado. Mientras en Latinoamérica se refuerza en sus mercados estratégicos (Brasil), es en Europa donde el Grupo asume un elevado compromiso de recursos y riesgos; además de probar a introducirse, aunque tímidamente, en EE.UU..

En Latinoamérica desde comienzos del nuevo siglo ha consolidado las actividades de banca comercial y también ha invertido en 
el desarrollo de la actividad de seguros y de financiación al consumo, apoyándose en un crecimiento externo (véase Tabla 6). De forma que al finalizar el 2006, Santander era la mayor entidad financiera de Iberoamérica por beneficios (véase Tabla 6) Esta región representaba un 34\% del beneficio atribuido del grupo y era uno de los pilares principales en los que se asentaba su fortaleza y su capacidad de crecimiento. Santander contaba en la región con 23,2 millones de clientes, 4.368 oficinas y 66.889 empleados localizados en ocho países, en tres de los cuales ocupaba posiciones de liderazgo (Brasil, México y Chile) ${ }^{18}$ como se puede observar en las siguientes tablas. También cabría añadir que se incrementaría aun más la presencia del grupo en Brasil en 2008, si finalmente se acepta la OPA presentada por Santander en consorcio con el grupo Royal Bank of Scotland y Fortis sobre ABN AMRO ${ }^{19}$ (la mayor operación financiera de la historia bancaria), y que permitiría al grupo incorporar el Banco Real de Brasil (el tercer banco del país por red de distribución y volumen de préstamos).

Tabla 6: Presencia en Banca comercial en Latinoamérica del Grupo Santander, 2006

\begin{tabular}{|l|r|r|r|r|r|r|r|}
\hline (Millones de euros) & Brasil & México & Chile & Argentina & Venezuela & $\begin{array}{c}\text { Puerto } \\
\text { Rico }\end{array}$ & Colombia \\
\hline Clientes (millones) & 7,5 & 8,1 & 2,4 & 1,9 & 2,6 & 0,3 & 0,3 \\
\hline Oficinas (número) & 2.026 & 1.039 & 397 & 261 & 282 & 140 & 88 \\
\hline Créditos a clientes en balance & 13.990 & 15.647 & 15.107 & 2.360 & 2.856 & 5.172 & 1.338 \\
\hline Recursos de clientes gestionados & 35.610 & 37.465 & 27.246 & 8.599 & 7.841 & 10.429 & 2.906 \\
\hline Beneficios atribuido & 751 & 528 & 528 & 148 & 146 & 26 & 24 \\
\hline
\end{tabular}

Fuente: Informe Anual Santander, 2006.

Al contrario que en la anterior etapa, desde comienzos de siglo, el grupo Santander hace una fortísima apuesta por incrementar su negocio en Europa (véase Tabla 7). Y para ello, desarrollará dos vías principalmente en base a un crecimiento externo. Por una parte, realiza

18 Santander Banespa es el cuarto banco privado de Brasil, Santander es la tercera entidad financiera de México y Santander es el primer grupo financiero de Chile por cuota de mercado y por beneficios.

19 En el segundo semestre de 2007 se ha cerrado por el consorcio mencionado, una OPA sobre el 95\% del capital social de ABN AMRO, que al grupo Santander le ha supuesto invertir 20.000 millones de euros. Esta operación se ha planteado con el fin, una vez que sea aprobada por el banco central holandés, de separar e integrar posteriormente los activos en los tres bancos compradores. Al Grupo Santander le correspondido los activos del Banco Real en Brasil y el Banco Antonveneta en Italia. Sobre este último ha pactado una operación de venta al banco Monte dei Paschi di Siena, por un precio de 9.000 millones de euros, cifra que es significativamente superior a los 6.600 millones de euros en que se había valorado el grupo Antonveneta en la OPA. 
una voluminosa operación de adquisición en el Reino Unido, en 2004, haciéndose con el total del sexto banco británico, Abbey (un banco líder en hipotecas que el grupo está orientando hacia la banca comercial). Y por otra, realiza nuevas adquisiciones que consolidarán y ampliarán el negocio de financiación al consumo en varios países comunitarios.

Tabla 7: Grupo Santander: Distribución de clientes por países

\begin{tabular}{|l|c|l|}
\hline Países & Distribución & Actividad \\
\hline España & $20,3 \%$ & $\begin{array}{l}\text { Banca comercial, financiación al consumo, banca privada y } \\
\text { mayorista, adm. Fondos pensiones, seguros }\end{array}$ \\
\hline Reino Unido & $24,6 \%$ & Banca comercial, financiación al consumo, gestión de activos \\
\hline México & $16,1 \%$ & Banca comercial, adm. Fondos pensiones, seguros \\
\hline Brasil & $10,9 \%$ & Banca Comercial, adm. Fondos pensiones, seguros \\
\hline Argentina & $6,1 \%$ & Banca Comercial, adm. Fondos pensiones \\
\hline Alemania & $5,1 \%$ & Financiación al consumo \\
\hline Chile & $4,6 \%$ & Banca Comercial, adm. Fondos pensiones \\
\hline Venezuela & $3,6 \%$ & Banca Comercial, adm. Fondos pensiones \\
\hline Portugal & $3,1 \%$ & Banca Comercial, adm. Fondos pensiones \\
\hline Resto países & $5,6 \%$ & $\begin{array}{l}\text { Banca comercial, financiación al consumo, banca privada y } \\
\text { mayorista, adm. Fondos pensiones }\end{array}$ \\
\hline
\end{tabular}

Elaboración propia en base a los datos extraídos del Informe Anual 2006.

La expansión del segmento Consumer Finance (financiación al consumo) ha sido decisiva en estos últimos seis años, con sucesivas compras que han permitido consolidar un área considerada estratégica para el grupo ${ }^{20}$, al afirmar que se corresponde con un segmento de elevado potencial de crecimiento y de rentabilidad, puesto que se apoya en la tendencia global del consumidor a financiar en una mayor proporción su gasto en consumo. A finales de 2006, Santander Consume Finance estaba presente en dos zonas geográficas: Europa (que engloba mercados maduros como el Reino Unido, Portugal, Italia, Alemania, Holanda, Austria, Noruega y Suecia con mercados emergentes como Polonia, República Checa y Hungría,) y tras la adquisición de Drive Financial culminada en diciembre de 2006, también en los EE.UU.. En total, esta red contaba, a finales de 2006, con 282 oficinas con 6.015 empleados, más de 9 millones de clientes y

20 Santander entro en el negocio de la financiación al consumo en la década de los 70, con la creación en 1972 de Bansafina y en 1978 de Hispamer. En 1987, inicio su expansión internacional con la compra de CC Bank. 
más de 100.000 puntos de venta concertados en Europa y EE.UU. (véase Tabla 8).

Tabla 8: Datos relevantes del Santander, 2006

\begin{tabular}{|l|c|c|c|c|}
\hline & \multicolumn{2}{|c|}{ Europa } & \multirow{2}{*}{ Iberoamérica } & \multirow{2}{*}{ Total } \\
\cline { 2 - 5 } & $\begin{array}{c}\text { Euro } \\
\text { Continental }\end{array}$ & $\begin{array}{c}\text { Reino Unido } \\
\text {-Abbey- }\end{array}$ & & \\
\hline Oficinas (número) & 5.772 & 712 & 4.368 & 10.852 \\
\hline Empleados (número) & 44.216 & 17.146 & 66.889 & $129.749(1)$ \\
\hline Créditos a clientes (millones $€$ ) & 271.687 & 190.512 & 60.172 & $523.346(2)$ \\
\hline $\begin{array}{l}\text { Recursos de clientes gestionados } \\
\text { (millones } € \text { ) }\end{array}$ & 301.238 & 205.860 & 141.381 & $743.543(2)$ \\
\hline $\begin{array}{l}\text { Base de clientes de banca comercial } \\
\text { (miles) }\end{array}$ & 12.196 & 16.904 & 23.235 & $68.822(3)$ \\
\hline $\begin{array}{l}\text { Patrimonio fondos y sociedades de } \\
\text { inversión (millones euros) }\end{array}$ & $83.566(4)$ & 8.307 & 27.965 & 119.838 \\
\hline $\begin{array}{l}\text { Patrimonio fondos de pensiones } \\
\text { (millones } € \text { ) }\end{array}$ & $11.398(5)$ & --- & 18.052 & 29.450 \\
\hline Beneficio ordinario atribuido al grupo & & $15 \%$ & $34 \%(7)$ & $100 \%$ \\
\hline $\begin{array}{l}\text { Distribución del beneficio ordinario } \\
\text { (\%) }\end{array}$ & $51 \%(6)$ & & & 6.582 \\
\hline
\end{tabular}

Elaboración propia en base a los datos extraídos del Informe Anual 2006.

(1) También se incluyen los empleados en gestión financiera y participaciones.

(2) Habría que añadir otros conceptos.

(3) Se incluyen además de los clientes totales de banca comercial (52.335), los clientes de banca de consumo (9.112) y los ligados a Administración de Fondos de pensiones (7.729), banca privada (85) y banca mayorista (11).

(4) 77.526 se administran en España y 6.040 en Portugal.

(5) 9.950 corresponde a España y 1.448 a Portugal.

(6) Este beneficio se distribuye de la siguiente manera: Red Santander: 22\%; Banesto: 9\%; Santander Consumer Finance: $8 \%$; Portugal: $6 \%$ y otras actividades: $6 \%$.

(7) Este beneficio se distribuye entre los países latinoamericanos en la siguiente manera: Brasil: 11\%; México: $8 \%$; Chile: $7 \%$ y el Resto países: $8 \%$.

Al finalizar el 2006, el Grupo Santander desarrollaba en la Europa Continental negocios en 12 países, que le han reportado el $51 \%$ de los beneficios ordinarios al finalizar 2006 (véase Tabla 8); de los doce países, destacaban España, Portugal y Alemania (entre los tres casi aglutinan un tercio de los clientes totales, como se muestra en la Tabla 7). El grupo Santander lideraba banca comercial y la banca privada en España, era el segundo banco privado por beneficios en Portugal y mantenía cuotas de mercado elevadas en financiación al consumo en España, Portugal, Alemania e Italia. Por otra parte, con la compra de Abbey, en el Reino Unido, no sólo se ha posicionado de forma privilegiada en un mercado principal en el mundo, sino que además ha incorporado a un $24,6 \%$ de clientes 
internacionales a sus cifras anuales, reportándole un $15 \%$ de su beneficio ordinario (Tabla 8).

La presencia en otros mercados del Grupo Santander, al finalizar el 2006, seguía siendo escasa, en comparación con el grupo BBVA. Muy reciente ha resultado el interés por Estados Unidos, donde en 2006, ha iniciado su expansión del negocio de banca comercial y fortalecido el de financiación al consumo con operaciones en ambos casos de crecimiento externo. Así, ha cerrado la adquisición del $24,8 \%$ de Soverign Bancorp (es el decimoctavo banco por activos de Estados Unidos con sede en Filadelfia y 800 oficinas en el noreste del país), además de adquirir el $90 \%$ de la financiera de automóviles Drive Financial.

Desde el año 2001, el grupo BBVA no ha variado significativamente ni las inversiones en Europa ni en los paraísos fiscales de Centroamérica donde tiene abiertas filiales (Islas Caimán, Antillas Holandesas y Panamá). En cambio, si que ha sido protagonista de una fuerte inversión transnacional que se ha focalizado hacia América, tanto Latinoamérica como, y, sobre todo Estados Unidos en América del Norte (se han multiplicado por cuatro los activos instalados en el sur de Estados Unidos en tan solo dos años); a la que cabe sumar una inversión experimental que se ha abierto en Asia, y en concreto en el potencial mercado financiero chino.

En Latinoamérica ha realizado inversiones muy selectivas, apoyadas en un crecimiento externo, que buscaban consolidar mercados y ampliar negocio. Así, ha apostado por reforzar su cuota en el mercado mexicano en 2004, adquiriendo las acciones que no poseía del grupo Bancomer, haciéndose con el total control sobre el mismo, además de adquirir el $100 \%$ de Hipotecaria nacional, la mayor entidad privada especializada en el negocio hipotecario del país. También refuerza un negocio más diversificado en Colombia, con la adquisición del banco Granahorrar que ha situado al BBVA como líder del mercado hipotecario del país; y en Chile, con la adquisición de Forum, compañía especializada en la financiación de vehículos; y en otros países del área donde incrementa su negocio de seguros. Por otra parte, también desinvierte en el mercado brasileño, al considerar que no tiene el tamaño crítico adecuado para alcanzar ventajas competitivas, niveles de eficiencia y de rentabilidad adecuados. Al finalizar 2006, en el área de América del Sur (Argentina, Bolivia, Chile, Colombia, Ecuador, Panamá, paraguay, Perú, republica dominicana, Uruguay y Venezuela) el grupo BBVA gestiona un volumen de negocio (agregado de inversión crediticia y el total de recursos de clientes) 
de 73.585 millones de euros, a través de una red de 1.613 oficinas y 28.609 empleados (Tabla 10).

En el nuevo siglo, la gran apuesta internacional del grupo BBVA se ha centrado sobre el sur de Estados Unidos (véase Tablas 9 y 10). Con una estrategia muy intensa, ofensiva y selectiva, apoyada en un crecimiento externo, el BBVA entra en el mercado estadounidense en 2004, primero en California, donde adquirió el Valley Bank de California y posteriormente en Texas, donde efectúa la compra del Texas de Laredo Nacional Bancshares. En 2006, refuerza su inversión en ambos mercados, con la compra en Texas Regional Bancshares Inc. y de State National Bancshares Inc., dos importantes franquicias bancarias en el estado de Texas. Y con ello, el grupo BBVA se ha convertido en el primer banco estatal de Texas. Con ello, el grupo sigue a los inmigrantes mexicanos e hispanos instalados de forma mayoritaria en esta región estadounidense (por ejemplo, en California hay censados diez millones de hispanos). Los hispanos y especialmente los mexicanos son el colectivo de población que más crece en EE.UU., por lo que el BBVA puede explotar las sinergias derivadas de su presencia en México a través de Bancomer.

Tabla 9: Aportación de las áreas de negocio al beneficio atribuido (millones de euros) BBVA

\begin{tabular}{|l|l|r|r|}
\hline & Áreas de negocio & $\mathbf{2 0 0 6}$ & $\begin{array}{c}\mathbf{2 0 0 6} \\
\mathbf{( \% )}\end{array}$ \\
\hline Banca minorista España y Portugal & $\begin{array}{l}\text { Servicios financieros, gestión de activos y banca } \\
\text { privada }\end{array}$ & 1.498 & $31,63 \%$ \\
\hline Negocios mayoristas & Empresas y corporaciones y negocios globales & 1.282 & $27,06 \%$ \\
\hline México y Estados unidos & $\begin{array}{l}\text { Negocios bancarios, pensiones, fondos de inversión y } \\
\text { seguros }\end{array}$ & 1.775 & $37,48 \%$ \\
\hline América del Sur & $\begin{array}{l}\text { Negocios bancarios, pensiones, fondos de inversión y } \\
\text { seguros }\end{array}$ & 509 & $10,75 \%$ \\
\hline Actividades Corporativas & \multicolumn{2}{|c|}{$(329)$} & $-6,95 \%$ \\
\hline Beneficio atribuido al grupo BBVA & 4.736 & $100 \%$ \\
\hline
\end{tabular}

Elaboración propia según datos recogidos en Informe Anual 2006.

Ahora bien, esta opción sobre este gran mercado americano se sigue potenciando, y en 2007, se ha procedido al cierre de la adquisición de Compass Banchshres, que tiene actividad en los estados de Alabama, Texas, Florida, Arizona, Colorado y Nuevo México. En cuanto sea efectiva, colocará al grupo BBVA entre los veinte principales bancos de EE.UU. con un liderazgo claro en el Sunbelt (franja que recorre el sur de EE.UU., el área de mayor crecimiento del país. 
La aventura asiática es muy reciente, en 2007 el grupo BBVA da un salto geográfico y se aleja de los mercados "cercanos" para iniciar un proyecto en países con diferente filosofía, cultura, etc., pero protagonistas de un elevado y potencial crecimiento. Elige un modo de entrada que no compromete demasiados recursos ni riesgos y que tiene un notable beneficio, y así establece una alianza estratégica con el grupo chino Citic Group. Con ello, el grupo BBVA se ha convertido en socio exclusivo para el desarrollo de los negocios de banca retail y mayorista en Asia, y de forma especifica en China. Esta operación se corresponde con la mayor inversión a realizada por una compañía española en este mercado, según informes del propio BBVA.

Tabla 10: Datos relevantes del grupo BBVA, 2006 (millones de euros)

\begin{tabular}{|l|c|c|r|r|r|r|}
\hline Áreas de negocios & $\begin{array}{c}\text { Inversión } \\
\text { clientes }\end{array}$ & $\begin{array}{c}\text { Depósitos } \\
\text { clientes }\end{array}$ & $\begin{array}{c}\text { Fondos de } \\
\text { inversión }\end{array}$ & $\begin{array}{c}\text { Fondos de } \\
\text { pensiones }\end{array}$ & $\begin{array}{c}\text { Cartera de } \\
\text { clientes }\end{array}$ & $\begin{array}{c}\text { Activos } \\
\text { totales }\end{array}$ \\
\hline Banca minorista España y Portugal & \multicolumn{1}{|c|}{118.113} & 63.479 & 44.824 & 16.583 & 19.032 & 124.292 \\
\hline México y Estados Unidos & $31.329(1)$ & $43.307(2)$ & 9.853 & 8.625 & 6.941 & $69.289(3)$ \\
\hline América del Sur & $17.366(4)$ & $21.667(2)$ & 1.575 & 31.872 & $\mathrm{nd}$ & $29.391(5)$ \\
\hline
\end{tabular}

Elaboración propia según datos recogidos en Informe Anual 2006.

(1) Inversión bruta excluido dudosos y la cartera hipotecaria histórica de Bancomer.

(2) Excluidos depósitos y repos emitidos por Mercados Bancomer.

(3) Excluidos Seguros.

(4) Inversión bruta excluidos dudosos.

(5) Incluye valores negociables.

\section{GRADO DE INTERNACIONALIZACIÓN DEL BBVA Y DEL}

\section{SANTANDER}

El grado de multinacionalización bancaria, como indica Duran Herrera y Lamothe Fernández (1991: 188) básicamente viene determinado por el nivel de diversificación geográfica alcanzado a través de sus filiales en el exterior, siendo secundaria la distribución internacional de la propiedad. Por ello, observaremos, el diferente nivel de internacionalización al comparar los activos totales de los grupos con los activos comprometidos en el exterior.

Si comparamos el nivel de internacionalización de la gran banca española (véase Tabla 11), se observa la distancia existente entre ambos y el elevado grado de compromiso internacional adquirido por el Grupo Santander. 
El Grupo Santander, en las dos últimas décadas ha realizado una apuesta definitiva en la internacionalización de su actividad como la estrategia principal para crecer, y así, a finales de 2006, el 62,36\% de los activos del grupo se localizaban en el exterior, el doble de los activos comprometidos en el año 1999, como se observa en la Tabla 11. En los últimos cinco años ha relanzado su expansión internacional de forma sobresaliente, y con ello ha incorporado 520.007 activos internacionales a las cifras del grupo (seis veces más de volumen que en 1999, cuando los recursos comprometidos en el exterior se limitaban a 76.734,9 millones de euros).

Tabla 11: Porcentaje de internacionalización de la gran banca española

\begin{tabular}{|l|l|r|r|}
\hline \multirow{2}{*}{ Conceptos } & \multicolumn{2}{|c|}{$\mathbf{1 9 9 9}$} & $\mathbf{2 0 0 6}$ \\
\hline \multirow{5}{*}{ BBVA } & Activos en el extranjero (millones $€$ ) & 50.076 & $107.688(1)$ \\
\cline { 2 - 4 } & Activos del grupo (millones $€$ ) & 238.166 & 411.916 \\
\cline { 2 - 4 } & $\%$ internacionalización bancaria (\% activos ext. / activos grupo) & $\mathbf{2 1 , 0 3 \%}$ & $\mathbf{2 6 , 1 4 \%}$ \\
\cline { 2 - 4 } & Incremento o disminución de internacionalización bancaria & \multicolumn{2}{|c|}{$24,29 \%$} \\
\hline \multirow{5}{*}{ Santander } & Activos en el extranjero (millones $€$ ) (2) & $76.734,9$ & $520.007(3)$ \\
\cline { 2 - 4 } & Activos del grupo (millones $€$ ) & $256.438,5$ & 833.873 \\
\cline { 2 - 4 } & $\%$ activos ext. / activos grupo & $\mathbf{2 9 , 9 2 \%}$ & $\mathbf{6 2 , 3 6 \%}$ \\
\cline { 2 - 4 } & Incremento o disminución de internacionalización bancaria & \multicolumn{2}{|c|}{$108,42 \%$} \\
\hline
\end{tabular}

Elaboración propia en base a los datos presentados en los informes anuales de varios años de BBVA y Santander. Los activos totales recogen los créditos a clientes, la cartera de negociación sin créditos, los activos financieros disponibles para la venta, las entidades de crédito, el inmovilizado y otras cuentas de activo.

(1) Estos datos incluyen BBVA Portugal (5.362), México y Estados Unidos (71.380) y América del Sur (30.496) millones de euros.

(2) Se refiere a los activos vinculados a la banca comercial localizados en el exterior., no pudiendo conocer el montante real de activos exterior de otras áreas. En el caso del BBVA, para el mismo periodo, se especifica que los activos de la entidad en el exterior están recogidos en las áreas denominadas BBVA América y BBVA Europa, correspondiendo estos, en su mayoría a banca comercial.

(3) Estos datos incluyen los activos en Portugal (44.304), Santander Consume Finance (46.917), Reino Unido (283.977) e Iberoamérica (144.809) millones de euros. Se puede destacar que dentro de Iberoamérica, en Brasil se han invertido 39.821, en México 50.032 y en chile 22.995 millones de euros.

El grupo Santander, en consecuencia, ha reestructurado sus áreas de negocio ${ }^{21}$, teniendo en cuenta las adquisiciones internacionales que ha realizado en estos años, y que sigue en la línea de incrementar notablemente (sirva de ejemplo, la OPA realizada sobre el ABN AMRO). Y en consecuencia, al finalizar el 2006, el negocio del grupo hay que observarlo

21 Entre 2004-2006, tanto BBVA como Banco Santander se han deshecho de participaciones industriales y financieras para disponer de liquidez a la hora de realizar sus compras internacionales. 
desde una perspectiva multinacional, en la que se combinan diversificación geográfica y operativa. Así, el negocio de banca comercial está implantando en Europa y en Latinoamérica; mientras que la banca al consumo básicamente se inserta en la Europa Comunitaria con la reciente incorporación de Estados Unidos. El negocio de banca privada y administración de fondos de pensiones es internacional, al igual que el negocio de bancaseguros (geográficamente, los ingresos por seguros se reparten: $31 \%$ en España y Portugal, 22\% en el negocio de Consumo, 21\% en Reino Unido y el restante $26 \%$ se ingresa desde América).

Por otra parte, los 107.688 millones de euros comprometidos en el exterior por el BBVA, a finales de 2006, suponen solamente la quinta parte de los que ha realizado el Grupo Santander. Por tanto, el grupo $B B V A$, si bien ha incrementado su nivel de internacionalización en un 25\%, duplicando los recursos generados multinacionalmente al pasar de 50.076 a 107.688 en estos seis años, aún está muy alejado de la gran apuesta transnacional practicada por el grupo Santander (véase Tabla 11).

\section{CONCLUSIONES}

Antes de 1992, la dinámica de internacionalización de la gran banca española había sido muy reducida y apoyada en la apertura de oficinas de representación y de un escaso crecimiento interno que pasaba por alguna apertura de sucursales en el exterior. Con carácter defensivo habían seguido a sus clientes en Iberoamérica, y en menor medida en Europa, además de buscar ciertas economías de aglomeración al situarse en plazas financieras principales. Tanto el grupo BBVA como el grupo Santander comprometen escasos activos y riesgos internacionalmente, puesto que carecen de dimensión y de recursos financieros para realizar operaciones de mayor volumen. El grupo BBVA se instalará, tempranamente, en Europa (si bien, Argentaria había abierto oficinas en Iberoamérica); mientras que el Grupo Santander, de la mano del Banco de Santander iniciará su andadura internacional en América Latina en la década de los 40, cuatro décadas antes de que comenzase la transnacionalización del $\mathrm{BCH}$, sobre la misma área.

El año 1992 marcó un antes y un después para la banca española. El cambio de contexto que se abre en España y en la Europa Comunitaria modifica los patrones de crecimiento de la gran banca española. El concepto tamaño adquiere un nuevo significado en un el 
nuevo mercado único de servicios financieros; y en consecuencia, tanto el BBVA como el grupo Santander, acometen ciertas inversiones en la Europa Comunitaria, pero con un carácter moderado, defensivo y oportunista. El elevado coste de entrada en otros mercados europeos así como la madurez de los mismos, obliga a la gran banca española a adoptar medidas de crecimiento externo amparadas en el establecimiento de alianzas y acuerdos de cooperación con socios instalados en los principales mercados comunitarios (Alemania, Reino Unido), así como en los más próximos (Francia, Italia). Tan sólo el mercado portugués resultaría asequible para la gran banca española, donde el BBVA abre sucursales mientras que el grupo Santander adquiere bancos locales.

Simultáneamente al cambio de contexto en Europa, también en Latinoamérica se está modificando el entorno competitivo, caminando hacia una liberalización y desregulación en la mayor parte de los países latinoamericanos, en los que se ofrece un nivel bajo de bancarización, escasa competencia inversora y una afinidad cultural e idiomática inexistente en otros mercados emergentes, y a un coste asequible. En consecuencia, la gran banca española, aún en proceso de consolidación, impulsa notablemente la colocación de activos en Latinoamérica durante toda la década de los noventa. Aplica, tanto en el caso del BBVA como del Grupo Santander, una estrategia ofensiva y gradual que aprovecha la experiencia internacional que ha extraído desde la etapa anterior para inyectar un elevado volumen de recursos y comprometer notables riesgos en la zona dadas las favorables expectativas del mercado latinoamericano. En base a un notable crecimiento externo que se sustenta en las tomas de participación mayoritarias y adquisiciones de bancos locales, tanto el BBVA como el Santander entran a operar y a liderar actividades de banca comercial en América del Sur. Al finalizar la década, y ya consolidadas posiciones lideres en los mercados más importantes de América Latina, las inversiones de la banca española comenzarán a especializarse. Esta discriminación tendrá carácter operativo y geográfico. Por una parte, aprovecharan el escaso desarrollo de los fondos de pensiones y de los fondos de inversión en el área, incorporando gestoras locales y también ofreciendo desde la red de oficinas instaladas productos de previsión financiera y de patrimonios colectivos, previamente diseñados en el mercado español.

Con el nuevo siglo, se introducen nuevas variables en las dos áreas principales de actuación de la gran banca española: la Unión Europea y Latinoamérica. Se impulsa la Unión Monetaria, a la par que se 
reducen las expectativas y las posibilidades sobre Latinoamérica. Es entonces cuando la gran banca española vuelve mayoritariamente sus ojos hacia los países desarrollados. Ahora ha adquirido una mayor dimensión y se está diferenciando como una banca de vocación internacional. En consecuencia, ya se encuentra en condiciones de acceder a los mercados bancarios más maduros situados en la Europa comunitaria y en Estados Unidos.

La Unión Europea se convierte en el gran objetivo del grupo Santander. Dentro del área, aplica una estrategia ofensiva y gradual, basada en actuaciones de crecimiento externo que tiene por fin consolidar e incrementar el segmento de financiación al consumo en varios países de centro, sur y este de Europa, adquiriendo participaciones mayoritarias en empresas locales; pero, sobre todo, la operación más importante la pactó sobre el Reino Unido, donde el grupo se haría con la totalidad de las acciones del quinto banco británico Abbey. Pero tampoco se olvida de Latinoamérica, donde de forma muy selectiva, y en base a adquisiciones, reforzará su cuota de mercado en Brasil, con nuevas compras, además reforzará el negocio de financiación al consumo, además de generalizar el ofrecimiento de pensiones, fondos de inversión y seguros en todo el área latinoamericana.

En cambio, el BBVA seguirá si mirar de frente a Europa, y volcará sus decisiones de internacionalización, en cualquier caso de menor envergadura que las del grupo Santander, hacia América del Norte. Priorizará los Estados Unidos de América, donde a partir de 2004, adquiere bancos locales en los estados sureños de Texas y California, buscando a los clientes hispanos. Estas operaciones siguen la estela de la previa consolidación y ampliación que también realizaría sobre México, al completar la toma de control sobre Bancomer.

A finales del 2006, no se habían dado por finalizadas las operaciones internacionales ni del BBVA ni del grupo Santander; es más, la internacionalización se ha convertido en una decisión ofensiva y estratégica para ambos grupos, como una vía rápida y fundamental de crecimiento, en un mundo sin fronteras financieras, que añade crecientes beneficios y nuevas capacidades. $Y$ así, ambos han anunciando dos importantes operaciones que pueden materializarse en el 2008, y que reforzaría la posición del Santander en el mercado brasileño, mientras el BBVA adquiriría una posición privilegiada en la costa californiana y en el continente asiático. 
La internacionalización de la gran banca española se ha convertido en un proceso complejo y gradual, que se ha impulsado notablemente en tan sólo la última década, y que no puede ser explicado en base a motivaciones simplistas (seguimiento de clientes nacionales en su expansión internacional, reducción del coste de capital, aprovechar ciertas regulaciones y diversificar el riesgo), y que requiere una explicación mucho más plural que acepta que los bancos se diversifican internacionalmente porque tienen ventajas competitivas (en propiedad, internalizadas y al localizarse transnacionalmente) que pueden explotar eficientemente en otros mercados, aprovechando su proximidad física y "psíquica". En consecuencia, la evidencia empírica en el caso de la banca española se adapta en mayor medida a la teoría ecléctica y al proceso secuencialista propuesto por la escuela de Uppsala.

\section{BIBLIOGRAFÍA}

ALIBER, R.Z. (1976) "Towards a Theory of International Banking", Economic Review, primavera, pp. 5-8.

Alonso, J.A. (1994) "El proceso de internacionalización de la empresa", Información Comercial Española, Enero 1994, n 725, pp. 126-143.

BERGES, A.; E. ONTIVEROS y F.J. VAlero (1990) Internacionalización de la banca. El caso español. Madrid: Espasa Calpe. Biblioteca de Economía.

BREALEY, R.A. y E.C. KAPLANIS (1996) "The Determination of Foreign Banking Location", Journal of International Money and Finance, no. 15 (4), pp. 577-597.

CARDONe Riportella, C. y L. CAZORla PAPIS (2001) "The Internationalization Process of Spanish Banks in Latin America: A Tale in Two Times", The International Journal of Bank Marketing, Vol. 19 (2-3), pp. 53-67.

CarRasco Caballero, M.C. (2000) "La banca española en Latinoamérica y la evolución reciente de los principales sistemas bancarios latinoamericanos", ICE, $\mathrm{n}^{\circ}$ 783, pp. 51-62.

CASSON, M.C. (1990) "Evolution of Multinational Banks. A Theoretical Perspective", en G. JONES (ed.) Banks as Multinationals. London: Routledge. 
CHEVALIER, J.M. (1995) L'Économie Industrielle des Stratégies d'Enterprises. Paris: Edt Montchrestien. Domat Économie.

DunNING, J.H. (1988) "The Eclectic Paradigm of International Production: A Restatement and Some Possible Extensions", Journal of International Business Studies, Spring, 19, pp. 1-31.

Durán Herrera, J.J. y P. LAmOthe Fernández (1991) "El proceso de multinacionalización de la banca española", ICE, n 692, pp. 187-205.

DUSSAUGE, P. y B. GARRETTE (1991) "Las alianzas estratégicas internacionales entre firmas competidoras: Un enfoque inductivo y estadístico", Información Comercial Española, n 692, Abril, pp. 113-129.

FAULKNER, D. (1995) International Strategic Alliances. Co-operating to Compete. London: McGraw-Hill Book Company.

GOLDBERG, L.G. \& A. SAUNDERS (1981) "The Determinants of Foreign Banking Activity in the United States", Journal of Banking and Finance, no. 5, pp. 17-33.

GoNZÁLEZ, F. (2002) "Las empresas multinacionales españolas: el caso del BBVA en Latinoamérica", ICE, $\mathrm{n}^{\circ}$ 799, pp. 127-135.

GraY, J.M. \& H.P. GRAY (1981) "The Multinational Bank: A Financial MNC", Journal of Banking and Finance, no. 5, pp. 33-63.

GROSSE, R. \& L.G. GoldBeRG (1991) "Foreign Bank Activity in the United Status: An Analisis by Country of Origin", Journal of Banking and Finance, no. 15, pp. 1093-1112.

GRUBEL, H. (1977) "A Theory of Multinacional Banking", Banca Nationale del Lavoro, Quartely Bulletin, diciembre, pp. 349-363.

JOHANSON, J. \& J.E. VAHLNE (1977) "The Internationalization Process of the Firm: A Model of Knowledge Development and Increasing Foreign Market Commitments", Journal of International Business Studies, 8 (1), pp. 23-32.

- \& P. WIEDERSHEIM (1975) "The Internationalization of the Firm-Four Swedish Cases", Journal of Management Studies, October, pp. 305-322.

KIM, T. (1993) "International Banking". en T. Kim (ed.) International Money and Banking. London: Routledge.

MAZA ARROYO, S. (1992) "Análisis de la actividad internacional de la banca española", ICE, n 704, pp. 66-76.

- (1994) "Internacionalización de la banca española. Alianzas y acuerdos de cooperación", ICE, n 735, pp. 104-117. 
OhmAE, K. (1991) El Mundo sin Fronteras: Poder y Estrategia en la Economía Entrelazada. Madrid: McGraw-Hill.

OlIVER, C. (1991) "Strategic Responses to Institutional Process", Academy of Management Review, no. 16, pp. 145-179.

RUESGA, S.M. y J.S. BICHARA (1998) "Inversiones españolas directas en América Latina en los 90", Boletín Económico del ICE, n 2574, pp. 9-18.

Rugman, A.M. (1981) Inside the Multinationals. The Economics of Internal Markets. London: Croom Helm.

SÁNChez PEINADO, E. (2001) "Internacionalización de la banca española: evolución y resultados en los años noventa", ICE, n 794, pp. 137-162.

- (2002) "Enfoques de internacionalización en el sector servicios: aplicación al sector bancario español", Revista Europea de Dirección y Economía de la Empresa, vol. 11, $\mathrm{n}^{\circ}$ 1, pp. 67-84.

Terreros, G. (1999) "Las instituciones financieras y la crisis", Perspectivas del Sistema Financiero, $n^{\circ} 66$, pp. 25-43.

VANDERMERWE, S. \& M. CHADWICK (1989) "The Internationalization of Services", The Services Industry Journal, January, pp. 79-93.

WIN, Y. \& H.V. PERLMUTTER (1977) "On the Identification of Frontier Sings in International Marketing", Columbia Journal of Wold Business, no. 12, pp. 131-139.

YanNOPOULOS, G.N. (1983) "The Growth of Transnational Banking", en M. CASSON (ed.) The Growth of International Business. London: Allen \& Unwin. 